\title{
The Effect of Direct Instruction on Spanish Language Acquisition in a Preschool Free-Play Environment: A Single-Case Design
}

Lucy Rose Scotti

Follow this and additional works at: https://researchrepository.wvu.edu/etd

\section{Recommended Citation}

Scotti, Lucy Rose, "The Effect of Direct Instruction on Spanish Language Acquisition in a Preschool FreePlay Environment: A Single-Case Design" (2015). Graduate Theses, Dissertations, and Problem Reports. 6593.

https://researchrepository.wvu.edu/etd/6593

This Thesis is protected by copyright and/or related rights. It has been brought to you by the The Research Repository @ WVU with permission from the rights-holder(s). You are free to use this Thesis in any way that is permitted by the copyright and related rights legislation that applies to your use. For other uses you must obtain permission from the rights-holder(s) directly, unless additional rights are indicated by a Creative Commons license in the record and/ or on the work itself. This Thesis has been accepted for inclusion in WVU Graduate Theses, Dissertations, and Problem Reports collection by an authorized administrator of The Research Repository @ WVU. For more information, please contact researchrepository@mail.wvu.edu. 
The Effect of Direct Instruction on Spanish Language Acquisition in a Preschool Free-Play Environment: A Single-Case Design

Lucy Rose Scotti, B.S.

Thesis submitted to the College of Education and Human Services

at West Virginia University

in partial fulfillment of the requirements for the degree of

Masters of Arts in

Educational Psychology

with an emphasis in Child Development

Barbara G. Warash, Ed.D., Chair

Amy Kennedy Root, Ph.D.

Jessica Troilo, Ph.D.

with Special Recognition to

Daniel Hursh, Ph.D.

and

Joseph R. Scotti, Ph.D.

Department of Learning Sciences and Human Development

Morgantown, West Virginia

2015

Keywords: direct instruction, preschool, Spanish, language acquisition

๔ 2015 Lucy Rose Scotti 


\begin{abstract}
The Effect of Direct Instruction on Spanish Language Acquisition

in a Preschool Free-Play Environment: A Single-Case Design

Lucy Rose Scotti
\end{abstract}

The predicted increase in Spanish speakers within the United States brings to light a new direction for preschool curricula. There are multiple, on-going arguments about the best time for children to learn a second language and what role critical periods for brain development play in second language acquisition. Although there are individual differences in development, the current study demonstrates that children can learn Spanish vocabulary words with an average of 30 minutes of instruction per week. Using a combination of direct instruction with developmentally appropriate practices, hands-on, and engaging activities, the teaching of Spanish vocabulary, themed and age appropriate for preschoolers, was incorporated into the West Virginia University Nursery School classroom. Six children from the afternoon collaborative class were chosen to participate in various forms of activities that incorporated English and Spanish into play-based interactions. Using prompts and feedback or praise, the progress of the children across days and over weeks was recorded and examined. Girls improved significantly on Spanish words correctly identified from pre-test to post-test, while boys showed little to no improvement. However, all children improved in fluency, or time taken to identify a pictorial response. Across the five-week intervention, all children demonstrated improved pronunciation and increasing independence and use within each set of themed words. A combination of direct instruction and engaging, interactive activities was shown to be beneficial in the learning of the children. This method of teaching can be easily incorporated into a more naturalistic classroom setting by providing opportunities of various types to slip vocabulary, directives, and bilingual instruction into the daily routine. 


\section{Acknowledgements}

I have multiple people to thank for their support throughout the experience of researching, designing, and implementing this study. First, I would like to thank Dr. Bobbie Warash, my committee chair, for her initial push to consider Educational Psychology and Child Development as my Master’s-level focus. I would also like to thank her for the support and expertise she gave in guiding me through multiple aspects of my research and writing. Second, I would like to thank Dr. Dan Hursh for providing initial research and design feedback over the course of his single-case design class. It was during his class that I prepared significant components of my research proposal and came to understand more about single-case design. Third, I would like to thank my other committee members, Dr. Amy Kennedy Root and Dr. Jessica Troilo, for their constructive feedback and suggestions that led me to expand my thinking, research, and final paper. Last, but certainly not least, I would like to thank my amazing parents. My father, Dr. Joseph Scotti, for his continued love, support, and encouragement, not only throughout my graduate school career and research, but also across all aspects of my life. Without him, my mind would not be nearly as filled with knowledge, understanding, reasoning, and compassion. I am also grateful my father has a sense of humor similar to mine, for it was certainly needed to make it through the countless hours of reviewing video recordings. Also, my mother, Lynn Clough, for unconditionally supporting me, loving me, and monitoring my health and well-being throughout this process, even if it was just from over the phone. My parents have made it possible for me to be successful in whatever I have set my mind to, and for that, I am so appreciative. 


\section{Table of Contents}

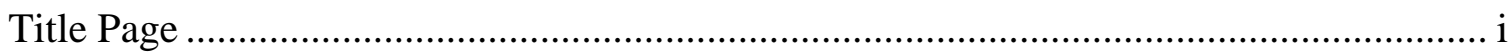

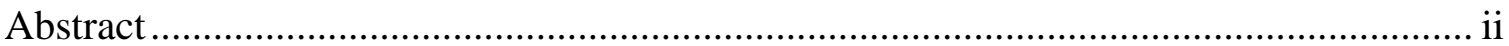

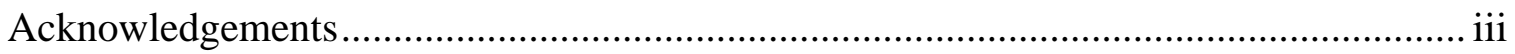

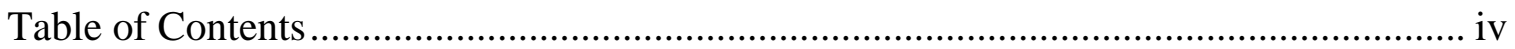

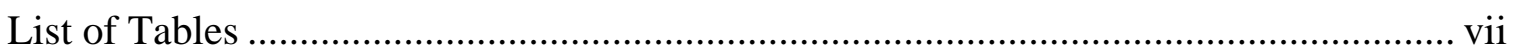

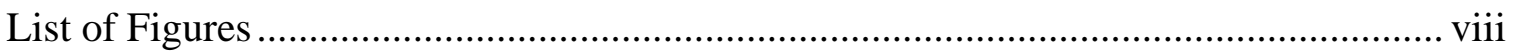

\section{CHAPTER I}

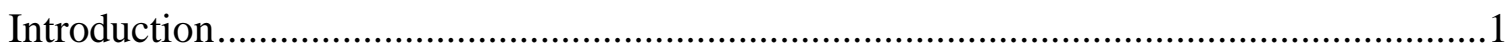

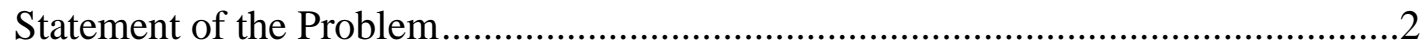

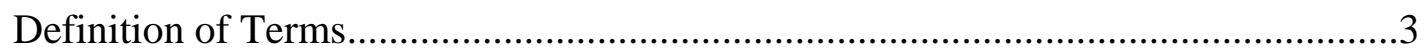

\section{CHAPTER II}

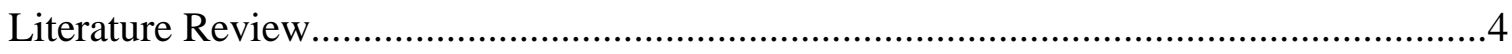

Language and Communication .........................................................................

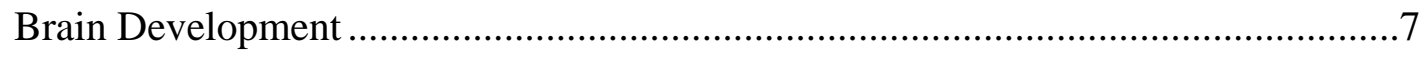

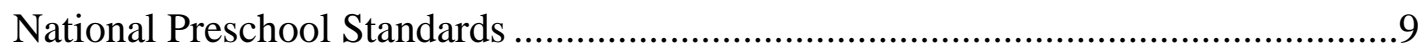

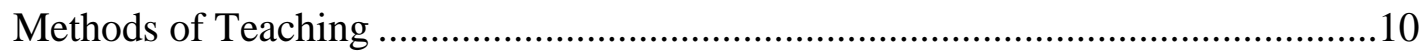

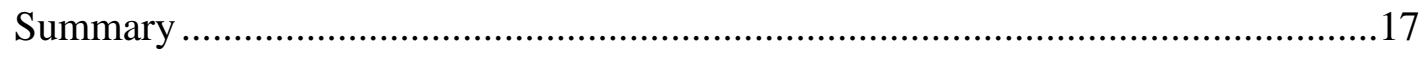

\section{CHAPTER III}

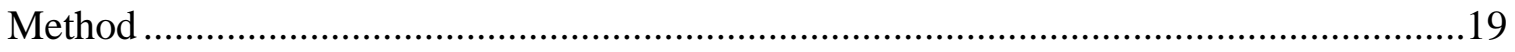

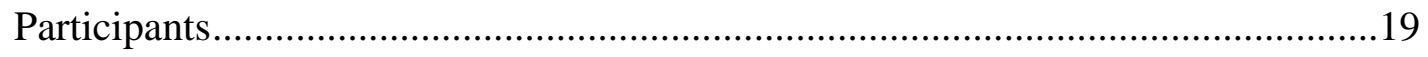

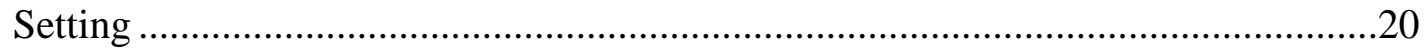


Design .21

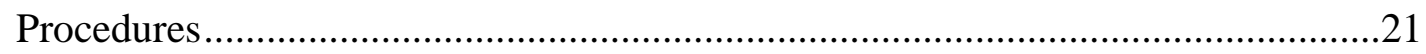

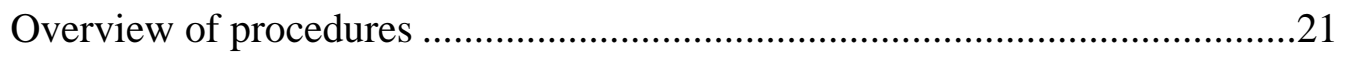

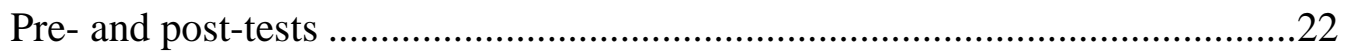

Learning context......................................................................................23

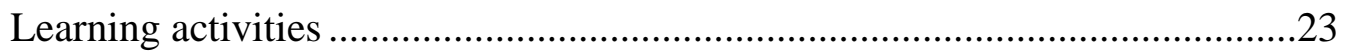

Data collection and scoring procedures............................................................25

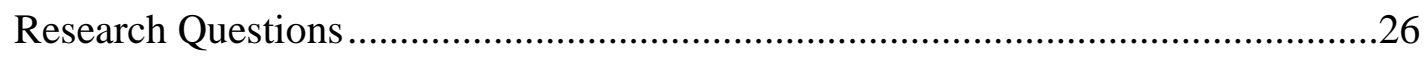

\section{CHAPTER IV}

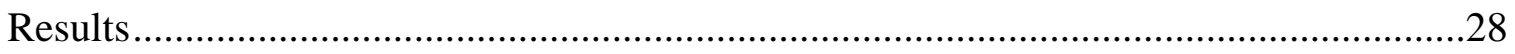

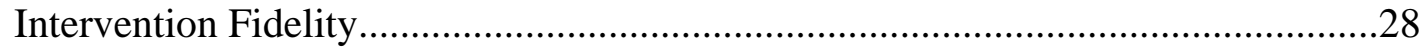

Analysis of Individual Participants ......................................................................29

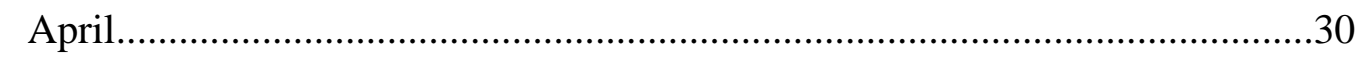

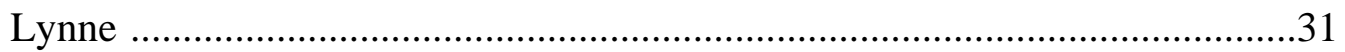

Sara

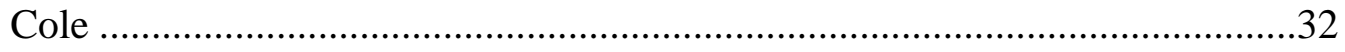

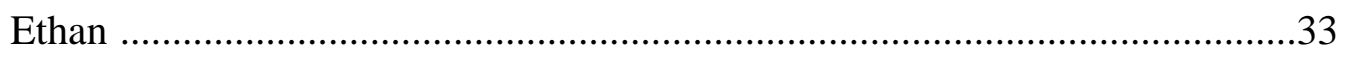

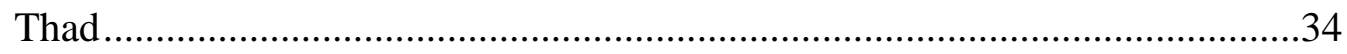

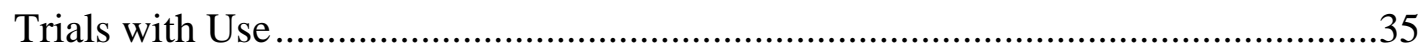

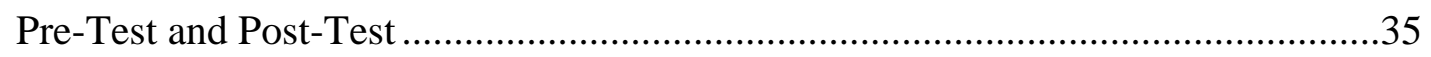

\section{CHAPTER V}

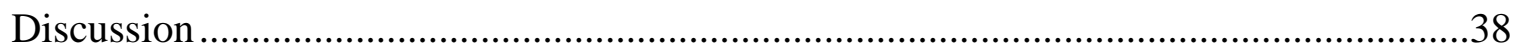

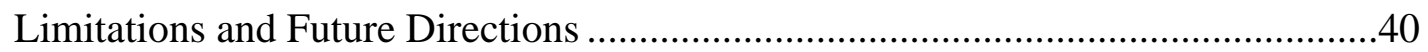


Application in Preschool Education........................................................................42

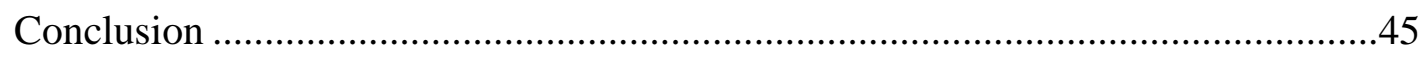

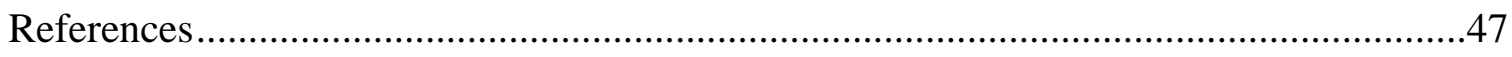

Appendix A. Sample Score Sheets for Pre-Test and Post-Test ..........................................68

Appendix B. Sample Lesson Plan for Themed Spanish Activities.....................................69

Appendix C. Sample Data Sheet for Coding Video Recordings of Activities ....................70 


\section{List of Tables}

Table 1. English and Spanish (in italics) Vocabulary Words for the Baseline Condition

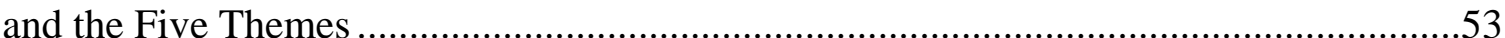

Table 2. Definitions and Examples for Instructional Trial Terms ...................................54

Table 3. Themes and Activities for Each Week, with the Times, Number of Trials, and

Seconds per Trial (s/t) for Each Child ..................................................................55

Table 4. Results from the Pre-Test and Post-Test of English and Spanish Vocabulary

Words for the Six Children, Including Number of Correct and Incorrect Words, and

Mean Time Taken to Select Correct and Incorrect Words .............................................57

Table 5. Correct Identification of Each English and Spanish Word on the Pre- and Post-

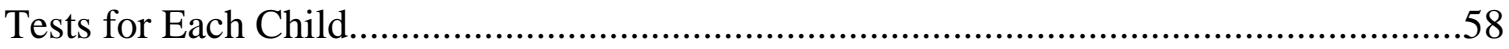




\section{List of Figures}

Figure 1. Example of a pre- and post-test picture card to assess receptive language in

English and Spanish......

Figures 2a-2j. Pronunciation and Prompts for April for Themed Words.........................60

Figures 3a-3j. Pronunciation and Prompts for Lynne for Themed Words ......................61

Figures $4 a-4 j$. Pronunciation and Prompts for Sara for Themed Words.........................62

Figures 5a-5j. Pronunciation and Prompts for Cole for Themed Words ........................63

Figures 6a-6j. Pronunciation and Prompts for Ethan for Themed Words........................64

Figures 7a-7j. Pronunciation and Prompts for Thad for Themed Words.........................65

Figure 8. Percent of Total Trials with Use .............................................................66

Figure 9. Percent of Trials with Use by Prompt Level.............................................67 
The Effect of Direct Instruction on Spanish Language Acquisition in a Preschool Free-Play Environment: A Single-Case Design

\section{CHAPTER I}

\section{Introduction}

The United States, long considered to be a "melting pot," has much diversity in terms of the prevalence of cultures, subcultures, and languages. The United States Census Bureau reports that $20 \%$ of families are speaking a first language in home other than English; 13\% of those are speaking Spanish (US Census Bureau, 2012). It is predicted that Hispanics will become a majority, rather than a minority, in the near future. This would also increase the prevalence and use of the Spanish language in many contexts, such as schools, media, and other daily interactions (e.g., grocery store, work, public transportation). Indeed, California has already begun incorporating Spanish into the common core state standards (San Diego County Office of Education, n.d.). Language and communication skills can either be an asset or a barrier when thinking of all the different communication styles, norms, and variations in vocabulary use and meaning. It is believed that the value of language increases when two languages are known and provides better tools to achieve success within language learning (San Diego County Office of Education, n.d.).

For young children, it is commonly thought that the ideal time to learn a second language is during the preschool years, while their brains are still making connections and the ability to differentiate between sounds is easier (cf. Birdsong, 2006). Between the ages of three and five years old, children are taking in an incredible amount of information from their surrounding environment, from behavior, to communication 
styles, problem solving skills, and language. Children are sorting through the techniques and skills that work best for them to succeed. Acquiring a second language, such as Spanish, with its rapid increase in prevalence, would prepare a child for more refined and diverse skills in the common developmental domains, diverse learning activities, and specific future job opportunities. It seems necessary for new generations to not just be exposed to the Spanish language for a few years, as an elective during high school, but come to learn this language alongside their native one. Research is contradictory about critical periods for children to learn a second language (Birdsong, 2006; Genesee, 2000;

Johnson \& Newport, 1989); however, earlier learning is likely to increase how natural or native a speaker will sound in that second language (Birdsong, 2006).

\section{Statement of the Problem}

The present study focused on a child's ability to learn Spanish vocabulary, intermixed with English, with little to no previous second language exposure. It took place in a free-play environment that is considered developmentally appropriate, where children are encouraged to make learning decisions based on their personal interests and skills. The study implemented a direct instruction technique during administration of vocabulary words. Through activities planned for individuals or small groups, direct instruction was utilized as a method of teaching words; data were collected to measure vocabulary use and acquisition over time. Thus, the problem addressed in this study was: Can young children learn Spanish vocabulary words through direct instruction within child choice time of a developmentally appropriate environment of a university preschool? 


\section{Definition of Terms}

Direct instruction was defined as one-on-one or small group (two to four children) instruction, during a teacher-led activity, using hands-on and interactive activities, where there is an intentional focus on teaching word meanings and usage for a specific set of vocabulary words (Wanzek, 2014). For the purpose of this study, vocabulary use was defined as the receptive or expressive language, understood or spoken/identified, during interactive teacher-child activities. Here, vocabulary acquisition was defined as the learning, retention, and recall, over time, of typical vocabulary words for a four-year-old child, with the focus here being on Spanish vocabulary. Developmentally appropriate practice (DAP) has been defined as a framework that “promotes young children's optimal learning and development” (Copple \& Bredekamp, 2009, p. 1). Used within a curriculum, developmentally appropriate practices serve to guide interactions, teaching moments, and lesson design and structure to create a basis of learning that is always just a bit more challenging for the child than their current level of learning. This practice recognizes that most or all of the learning domains are interrelated throughout learning and promotes the utilization of scaffolding, decision-making, and problem solving within a learning context (Copple \& Bredekamp, 2009). 


\section{CHAPTER II}

\section{Literature Review}

\section{Language and Communication}

Language is a part of everyday life; there is no way to continuously avoid using it in some form. Communication styles vary between cultures and even close regions in some areas, so language barriers can be a common nuisance. The United States Census Bureau (2012) projects that, through 2020, there will be a slight increase in the number of Spanish speakers. This primarily refers to Spanish speakers from Latin America. Across the world, there are many differences between dialects, accents, vocabulary, and slang in Spanish, just as in the English language. Within the United States, Spanish is the primary language of those who speak a language other than English (Shin \& Ortman, 2011). The

predicted increase in Spanish as a first language brings to light a new curriculum for early education. Rather than being a second language, generally learned in secondary education, it would seem to be a practical move, if not a necessary one, to begin Spanish instruction during the preschool years.

The rationale for beginning language learning at younger ages includes the dramatically increasing movement towards globalization, diversity, multiculturalism, and multilingualism (Gürsoy \& Akin, 2013). Typically, the learning of a second language takes place at the high school and collegiate levels. Gürsoy and Akin (2013) note that second language learning is now taking place as early as the elementary grade levels. It was previously thought that younger children would have anxiety about learning another language and being evaluated on their acquisition by peers and teachers; however, Gürsoy and Akin (2013) show that this is not the case. This raises the question as to the 
benefits of learning a second language at the preschool level when children's brains are constantly making new connections and linguistic anxiety may be minimal.

In a study conducted within Greek State Kindergarten classrooms with students learning English as a second language, the aim was to present children with positive attitudes about foreign language acquisition and multiple means of representation to learn language skills (Griva \& Sivropoulou, 2009). Similar to various components of the present study, these researchers used a pre-test and post-test to assess children's oral language skills, receptive language, and word production. Themed words were also used in the study by Griva and Sivropoulou (2009), similar to those chosen for the current study, such as colors, food, home objects, persons, and body. With similar procedures (use of receptive language, prompts, and small groups) and items for learning (themed words), even with a slightly older sample (preschoolers aged 4 to 6 years), it could be concluded that similar language acquisition patterns would be expected in the current investigation.

Children are able to learn language and other components of behavioral and social development through adult modeling and by simply being exposed to natural conversation and social situations. Neu (2012) discussed that to learn a second language, the knowledge of a child's first or native language must also be applied to the social and linguistic experiences, building upon the natural application of linguistic rules. Bilingual education and immersion is an increasing approach for teaching English to non-native speakers (Barnett, Yarosz, Thomas, Jung, \& Blanco, 2007). With this in mind, dualimmersion curriculum in early childhood classrooms could have similar effects with native English speakers learning Spanish, especially while incorporating components of 
direct instruction.

For a child, learning does not take place singularly, but across multiple interactive domains, such as, cognitive, linguistic, and kinesthetic (e.g., when learning to tie their shoes, a child may think about how to complete the task, recite a rhyme to remember the steps, and do the movements all at once or in separate steps, yet leading to the final outcome of a tied shoe). Despite differences in vocabulary, emphasis of definition, and body language norms across cultures, language is a necessity of life. Goodrich, Lonigan, and Farver (2013) studied Caucasian and Latino preschool students and found a correlation among print knowledge (letter symbols) and phonological awareness (letter sounds) across languages. These were not correlated with vocabulary knowledge (meaning of the words). Similarities between visual and audible representation of the English and Spanish alphabet were evident, except for a handful of words, but vocabulary was more of a language-specific skill (Goodrich et al., 2013) due to differences in vocabulary use, slang, and cultural norms.

When learning language, Yeung, Siegel, and Chan (2013), in teaching English to Spanish speakers, found that phonological awareness (knowing and identifying sounds in words and the environment) plays a prominent role in identifying and manipulating speech and in predicting later reading outcomes. With similarities between many English and Spanish words, phonological instruction would not only be beneficial, but necessary, to the direct instruction processes of learning Spanish as a second language during the preschool years. Other benefits of phonological awareness discussed by Yeung et al. (2013) include the association with reading development for a second language (Spanishspeaking learners of English, in their article, which is easily transposed to English- 
speaking learners of Spanish), word decoding (applying letter-sound relations and patterns to correctly pronounce words), and segmental phonology (vocabulary expansion that produces more knowledge of words with similar sounds).

\section{Brain Development}

Learning a second language involves various processes and experiences, which interact with each other over time. Prior to adolescence and puberty, a child's brain is still making connections. When learning takes place, connections are created between neurons that are near and more distant from others in the brain (Genesee, 2000). When children hear another language they do not know, they tend to ignore it because to them it comes off as "nonsense.” The brain filters these sounds, and at first "ignores” what it does not know or understand. With more exposure and understanding, the brain begins to differentiate between sounds and registers these with the auditory cortex (Genesee, 2000). With this in mind, exposure and practice come into play when learning a second language, creating a schema for that language.

If children are able to differentiate between the voices of a familiar caregiver and a stranger, the question could be raised as to whether they are able to understand familiar sound patterns, as well. New research suggests that children as young as infancy have the ability to recognize sound patterns that are similar to words (Gómez et al., 2014, as cited in Language Structure, 2014). These authors discuss how brains may be wired to favor certain syllable combinations, as most, if not all, words in certain languages begin with particular sounds (e.g., $b l$ for "blink” versus $l b$, which is only found in a few Russian words). With this specific language ability in mind, it could be gathered that even if another language is being spoken around the child, they could still recognize similar word 
and syllable patterns to those of their native language, and code them as word-like, even without fully understanding the meaning. This is supported by findings of research conducted with newborn infants in Italy whose brains reacted differently to various sound combinations (word-like: blif versus "nonsense”: lbif). This suggests that even without much prior language exposure and experience, the infants still innately understood how words should sound (Language Structure, 2014).

Researchers (Birdsong, 2006) have argued the idea of a critical period for second language learning, meaning that once the window has passed, generally after five years of age, it will become increasingly difficult to learn and become native-like in second language acquisition. Other researchers suggest that the critical period spans from infancy toward the end of puberty (Johnson \& Newport, 1989; Snow \& Hoefnagel-Höhle, 1978). During infant and toddler stages, children are taking in many aspects of language, from voices they recognize to sounds and patterns, leading up to vocabulary practice and acquisition, increasing as they age.

Birdsong (2006) discusses the notion of a critical period and notes how there are well over a dozen variations in terms of critical ages and the factors (e.g., brain development, cognitive capacity, and speed of processing) that help or hinder learning of a second language. Although age of exposure and age of acquisition, and the effects they have on learning a second language, do seem to be important, it appears that individuals can still acquire additional languages well into adulthood. The bigger issue is how natural, or native, the speaker will sound in that second language (Birdsong, 2006). Learning at younger ages will allow for more development in the pronunciation and general fluency with a second language, as compared to waiting until the junior or high 
school years.

\section{National Preschool Standards}

In some ways, the foundation is already set in early childhood to begin the acquisition of a second language. Quality early childhood programs abide by the early learning content standards within their states, as most states have standards for preschool classrooms. For example, in 2012, West Virginia met eight of the ten benchmarks on the National Institute for Early Education Research (NIEER) Quality Standards Checklist. Several of these benchmarks included the utilization of the early learning standards, specialized training for teachers, continuing education (teacher in-service), and staff-child ratios (Barnett, Carolan, Fitzgerald, \& Squires, 2012). The West Virginia Early Learning Standards Framework consists of content standards that were developed based on the universal Common Core, which many states are in the process of implementing. Common Core standards focus on mathematical and language arts and literacy skills that children should be developing from kindergarten through grade 12 (Porter, McMaken, Hwang, \& Yang, 2011). With these educational goals for the future, a 37\% increase in four-year-old enrollment in public early childhood education from 2002-2012, and access to a universal preschool system for all four-year-olds currently in place (Barnett, Carolan, Fitzgerald, \& Squires, 2012), teachers of preschool students are better able to support children and build upon skills needed for language and communication.

The Early Learning Scale (ELS), developed by the National Institute for Early Education Research (Riley-Ayers, Garcia, Frede, \& Brenneman, 2011a, 2011b), is utilized to measure how West Virginia preschools are meeting the early childhood standards. These standards provide a guide for extending learning experiences and 
promoting school readiness for all learners. Most states have similar measures of child progress. One section of the ELS framework that emphasizes language and literacy development provides specific examples of what the children should be able to do, such as "shows growing ability to hear and discriminate separate syllables in words” (p. 33) and "recognizes words as units of print that are separated by spaces” (p. 35; Riley-Ayers et al., 2011b). The acquisition of phonological awareness, part of the language and literacy domain in this framework, is the foundation for learning a language, including a second language. Linking the early learning standards to the West Virginia Content Standards, phonological awareness was taught within the current study through a variety of different activities incorporating English and Spanish words across a variety of modalities. Some specific content standards from the Language and Literacy (LL) and Social Emotional Development (SE) domains that were addressed through the activities in this study included: comprehending and expanding on oral language (LL 1.4), taking turns in speaking (LL 1.6), recognizing a word as a unit of print (LL 2.12), showing awareness of beginning and ending sounds of a word (LL 2.11), persisting in completing a task (SE 4.4), following routines and rules in play (SE 2.11), and understanding different cultures and languages (SE 3.3; West Virginia Department of Education, 2010).

\section{Methods of Teaching}

Through years of experience, early childhood educators have discovered and become comfortable with their favored teaching techniques. Developmentally appropriate practices have been the norm or "mantra" for years in the field of early childhood education (Copple \& Bredekamp, 2009). However, mixed methods of instruction within the realm of developmentally appropriate practice are becoming more acceptable and 
common. Head Start developed a range of strategies on a teaching continuum, recommending teacher-directed instruction to support child learning (Warash, Curtis, Hursh, \& Tucci, 2009). Although both child and adult interactions shape play and learning within a classroom social context, this continuum begins to question the rationales for direct instruction versus child-initiated instruction (Warash et al., 2009), leading to the conclusion that a combination of the two could provide the optimal outcome for child learning. Exploring the use of direct instruction in a developmentally appropriate classroom is a key basis for the present study and the model on which the lesson plans and activities were designed to incorporate child interests and exploration.

A study by Miller and Dyer (1971) provides a good historical example of the interest in comparing multiple types of instruction to enhance the learning of preschoolers in Head Start. Miller and Dyer compared four instructional strategies, looking at the first and second years of a three-year longitudinal study. Those methods included traditional (official Head Start program) teaching methods, the Bereiter-Engelmann program (a variant of direct instruction), the DARCEE program (Demonstration and Research Center for Early Education at George Peabody College), and the Montessori approach. The Bereiter-Engelmann program focused on the "acquisition of linguistic and numerical skills by use of verbal instruction, imitation, and reinforcement, and de-emphasized sensorial stimulation and manipulation” (Miller \& Dyer, 1971, p. 5). On the other hand, these authors described the DARCEE program as focusing on the attitudes and motivation toward learning, although still incorporating stimulation and reinforcement. The focus in the Montessori approach, according to Miller and Dyer (1971), was on developing persistence, independence, and self-discipline, and de-emphasizes the use of 
reinforcement and verbal instruction. Lastly, these authors described the traditional Head Start program as having a focus on social and emotional development, while incorporating role-play, and again, de-emphasizing reinforcement and verbal instruction. Miller and Dyer (1971) sought to determine which of these four methods had the greatest positive impact on preschool children when learning language and mathematical skills.

The results from Miller and Dyer (1971) were mixed depending on the outcome measure of interest. For example, the traditional and Bereiter-Engelmann methods, which differed on the use of reinforcement, both had higher scores on a measure of persistence than the other two groups. Both the Montessori approach, which emphasized intellectual curiosity, and the Bereiter-Engelmann method, showed equally high scores on a measure of curiosity. The Bereiter-Engelmann method also produced the highest scores on measures of arithmetic and sentence production, while the DARCEE method produced equally high scores on arithmetic and the highest scores on verbal-social-participation (Miller \& Dyer, 1971). Although one might expect a Montessori approach to have resulted in more cooperative behavior among children, it was the Bereiter-Engelmann method that was associated with the least aggressive behavior in the children. One could conclude that the Bereiter-Engelmann method, which most closely resembled direct instruction of the methods studied, appears to have been the best at promoting certain verbal skills; other teaching methods had positive impact on related important areas of child development. As such, the argument for employing mixed methods when teaching is not a new one.

A specific program developed to teach reading skills utilizing direct instruction is DISTAR: Direct Instruction System for Teaching Arithmetic and Reading. The What 
Works Clearinghouse (2007) described direct instruction as "teaching techniques that are fast-paced, teacher-directed, and explicit with opportunities for student response and teacher reinforcement or correction” (What Works Clearinghouse, 2007, p. 1). In an intervention report, the What Works Clearinghouse (2007) examined research comparing direct instruction, DISTAR, and Language for Learning and determined: (a) that, in general, the literature had poor quality research designs, and (b) that little difference could be found between methods of instruction. This appears to be a blow against reading programs in general; however, research by Williamson (1970) suggested otherwise. Williamson compared several reading programs, including DISTAR and Phonetic Keys to Reading (PKR). The overall findings, comparing four classrooms, found, as in the What Works Clearinghouse (2007) review, that there were no statistically significant differences in final reading scores by type of reading program. However, Williamson (1970) took the extra step of examining low, middle, and high-performing readers, based on their initial reading scores. She found that high-performing readers all improved equally regardless of program, but middle- and low-performing readers showed greater improvements under the DISTAR program (Williamson, 1970). This suggests that initial reading level is a good indicator of which children may benefit most from which programs. In considering works such as that by Miller and Dyer (1971), mixed methods may be important, but which methods work best for which children must also be considered. Good readers likely have the skills and motivation for learning language and tying in the other aspects of language that work together. That being said, readers with skills that are not as strong may need more reinforcement and verbal instruction to perform at similar levels. 
In early childhood education, large groups, one-on-one time, peer helpers, interactive activities versus drills, or natural teaching moments and modeling are all acceptable methods of teaching. Vocabulary, however, is best acquired when the learner is active in their exploration, creating more opportunities for the child to use and remember the words (Jalongo \& Sobolak, 2011). To strengthen learning and recall of vocabulary, Rowe, Silverman, and Mullan (2012) reported that verbal (naming objects) and non-verbal (showing pictures or objects) examples, although processed separately by children, help to achieve this outcome. Similarly, developmentally appropriate practice suggests using language models that help shape language learning and skills, also influenced by the environment (Copple \& Bredekamp, 2009). By incorporating visual prompts throughout the classroom (text and pictorial representations of common vocabulary words or short commands, i.e., table, wash hands) the meaning of spoken words is reinforced, allowing for another connection to process and link all forms of the word and language together.

With regard to direct instruction, Ramirez and Jones (2012) included an overview of three studies and the preferred methods of teachers and students learning various aspects of grammar and vocabulary for those learning English as a second language. Comparing communicative- and grammar-based approaches, Ramirez and Jones (2012) obtained mixed results and could not determine which method was preferred. These authors concluded there was a need for further research on this topic and the usefulness of direct instruction.

As discussed above, to build upon vocabulary, it is more beneficial to include multiple means of representation: verbal, visual, audible, and haptic. Sibold (2011) 
discussed how to build vocabulary for English language learners and noted that the most effective strategies involved direct instruction. Logically, direct instruction might be the most effective for learning any language, or a second language, such as English speakers learning Spanish. Incorporating learned vocabulary throughout the day, emphasizing the utilization of the means of instruction, would provide all learners with something that will work for them. As previously mentioned, adult models support child learning by simply listening to conversation, hearing oral exchange, and picking up on the “unspoken” rules of communication. Developmentally appropriate practice highlights the benefits of carrying on a more adult-like conversation, allowing for expansion on vocabulary (here, in both English and Spanish), and allowing opportunities for the introduction of new words (e.g., expansive vocabulary, such as synonyms), which can also be easily incorporated into play.

Direct instruction, although generally individualized, can also be beneficial when done in small, interactive groups. With each child's learning on varying levels, cooperative learning can act as a motivator for children’s involvement. For children in Taiwan, the idea is supported that motivation for involvement and speaking are enhanced when learning takes place in a cooperative environment (e.g., Kao, 2003, as cited in Alghamdi \& Gillies, 2013). The cooperative learning setting allows those children who may be behind others to benefit from more advanced peers, as well as all taking part in discussions about tasks (Alghamdi \& Gillies, 2013), using relevant vocabulary.

Through a form of direct instruction and attention paid to phonological patterns, younger children can take their current knowledge of the English language and apply it to learning Spanish. In an experiment using a mnemonic technique, the child takes a 
familiar English word and uses it as a base for the new Spanish word (Pressley, Samuel, Hershey, Bishop, \& Dickinson, 1981). These authors provided an example of this, using the English base word "cart" to remember the Spanish word for "letter," which translated, is carta. Code-mixing, or code-switching, consists of switching between languages, generally words within a longer phrase (Greene, Peña, \& Bedore, 2012). For example, a native Spanish speaker begins a sentence in English, yet cannot think of a specific vocabulary word, and switches to Spanish, where she is able to find the correct terminology. It could be concluded that between the two noted techniques, Spanish language would become more expansive and serve as a more meaningful experience for a child, especially when tied to their native language.

Another method that could potentially be used in a direct instruction setting is the interaction approach. Through this approach, language is used as a means of communication, but instead of focusing on accuracy, the main idea is to relay meaning (Philp \& Tognini, 2009). In reference to the above-mentioned ideas of code-mixing or code-switching by Greene et al. (2012), it is discussed that when code-switching, there is generally a pause between languages to find the right words again (Amir, 2013). In this case, the authors discuss students learning English as a second language, but the concept of the pause could be reversed to English speakers learning Spanish, because even in your native language, there are times when it becomes difficult to find the words you want, this is increasingly so in a combination of two languages.

In conclusion, although there are many approaches to learning not only a native language, but a foreign one, direct instruction certainly warrants a further look. The benefits of learning a second language overall, but starting at a younger age, surpass 
anxiety or learning challenges as there are now various ways to accommodate all learners. It could be surmised that strategies used to teach those learning English as a second language would also be beneficial to those learning Spanish as a second language. With the Spanish language becoming more prevalent in the United States, acquiring a second language to be able to communicate more with others is becoming a critical skill. As for young children starting out, learning another language through the connection of school and home, can increase self-confidence in the second language, among other academic benefits and cross-domain learning (Hummel, 2013).

\section{Summary}

In summary, there are many components of language and communication that rely on each other when a child is learning a first or second language. As rates of Spanish speakers within the United States are on the rise, it is important to take into account the second language learning opportunities for young children. Beginning second language learning within the preschool years, rather than waiting until adolescence, allows the child to make more connections and retain the information better, as well as sounding more native-like in their speech. This is certainly feasible and would benefit the children greatly, with a new and growing focus on diversity and multiculturalism.

The argument of a critical period for language development is on going, especially as to what age ranges encompass that critical period; regardless, it appears easier to learn language at a younger age. It is important to keep in mind that the domains of learning all interact with each other. As such, direct instruction in early childhood education would likely benefit second language learning when utilizing visual, verbal, auditory, and haptic cues in an interactive and engaging set of activities. As has been shown, direct instruction 
within a developmentally appropriate learning context is a method of choice teaching language to young children.

The findings presented in this study are evidence that children can learn a second language and retain the information over time. This knowledge provides the basis for understanding how language programs can be implemented and benefit preschool children learning a second language, which is an area of importance in the Early Learning Standards. In addition, the findings help teachers of young children, who are required to use a developmentally appropriate approach, understand how to incorporate direct instruction within their classrooms and still abide within the philosophy of developmentally appropriate practice. 


\section{CHAPTER III}

\section{Method}

\section{Participants}

The participants were preschool children from the afternoon class at the West Virginia University Child Development Laboratory School, also known as Nursery School. This classroom is a universal preschool classroom that operates under the auspices of the West Virginia State Department of Education (WV DoE), the West Virginia Department of Health and Human Resources (WV DHHR), and the College of Learning Sciences and Human Development at West Virginia University.

The ages of the afternoon class range from four to five years. The majority of the children enrolled at the Nursery School are Caucasian. The children of the afternoon class are typically developing. Many of the families with children enrolled have at least one parent or family member affiliated with the university, including siblings who have attended the Nursery School in previous years. The majority of the parents with children in this classroom are considered professional, with approximately $71 \%$ holding a Bachelor's degree or higher. Of the remaining parents, an estimated 29\% had obtained some type of specialized training or had partially completed college (at least one year). The aforementioned status of families was determined from a previous research study (DeVito, Warash, Root, \& Curtis, 2013); for the present study, more specific demographics were gathered at the start of data collection (Fall of 2014). There were few differences between these two studies in the family demographics, except the estimated number of parents who completed college was higher in the present sample.

Six children were purposively selected from the afternoon class: three girls and 
three boys. Originally, the selection was to allow for each child to have an equal chance of being selected, regardless of gender, performance level, or other differentiating characteristics. However, the final six were chosen based on several attributes, including the limited number of boys in the classroom. Children were ruled out as potential participants if they had communication difficulties or behavioral issues, such as the inability to participate in an ongoing task. A consideration for inclusion was the expected ability to focus on an activity or short-term task.

The selected children were: (a) April, a four-year, seven-month-old girl; (b) Lynne, a four-year, six-month-old girl; (c) Sara, a four-year, five-month-old girl; (d) Cole, a four-year, six-month-old boy; (e) Ethan, a four-year, nine-month-old boy; and (f) Thad, a four-year, five-month-old boy (names are fictitious). All participants were Caucasian and had from one to three siblings. Mothers completed the consent forms and demographic questionnaires, all reporting being Caucasian, married, and having a Bachelor's, Master’s, or law degree, with household incomes ranging from $\$ 50,000$ to over $\$ 100,000$.

\section{Setting}

The study took place at the Nursery School, a laboratory school environment for college-level students to observe and work with children, as well as refine their own teaching skills through observation and hands-on experiences. The children at the Nursery School experience a child-directed free-play environment, with specified times for student teacher-led activities (45-60 minute centers) on a daily basis. The morning class consisted of 20 three-year-olds, while the afternoon class was made up of 20 fourand five-year-olds, predominately girls. The Nursery School has an open floor plan, with labeled areas broken up for various child interests, such as blocks, art, and housekeeping 
(dramatic play). The materials and furnishings are child-sized and age-appropriate. There is a separate office for staff and a kitchen area. The class participates in individual and small group activities, depending on the number of children participating at each activity during center time. Video recordings and data were only collected on the six selected participants.

\section{Design}

The pre- and post-tests took place during regularly scheduled school hours. For this, the children were taken to a private area in the classroom. The intervention took place during the normal classroom routine of teacher-led activities three days a week, on Mondays, Tuesdays, and Fridays. The original plan was to use a variation of a changing criterion design, in which children would need to demonstrate knowledge and use of five vocabulary words within a theme before moving on to the next set of themed words. This was determined not to be practical within this setting due to the need to fit the design into the standard instructional center format that is used at the Nursery School. Instead, each child attended three themed activities each week, each activity providing a different context for learning and using the Spanish vocabulary words (see the section titled Learning Activities, below, for a discussion of the activities). The theme and related words changed each week, regardless of the level of proficiency each child attained on the prior themed words.

\section{Procedures}

Overview of procedures. West Virginia University Institutional Review Board approval was provided for this research study. Children were ruled out as potential participants if they had communication difficulties or behavioral issues, such as the 
ability to participate in an ongoing task. Again, six children were selected to participate; three girls and three boys. The researcher provided a letter describing the study and a schedule of activities and discussed it with the parents. Parents had the opportunity to ask questions and agree to or decline participation of their child. Once parental consent was received for the six children asked to participate, the researcher individually gave each child a pre-test in English and Spanish. After this, the baseline phase began, where children identified family members in English. The children were questioned by the researcher during baseline as to what they thought the Spanish words for the family members were. Responses ranged from “I don’t know” to made up nonsense words. This demonstrated that the children did not use Spanish unless prompted or taught. The fiveweek intervention consisted of direct instruction activities, conducted in English and Spanish. Each week consisted of five themed words, which the children practiced and used throughout the planned activities. After the intervention was completed, the children took a post-test, again, in English and Spanish.

Pre-test and post-test. A pre-test and post-test were individually given to each of the six participants in a combination of English and Spanish (see Figure 1 for an example of a pre- and post-test picture card). The pre- and post-tests were made up of words from the intervention; words chosen to be identified in English and Spanish were randomly selected. The pre- and post-tests required the children to identify the word by pointing at the correct picture (receptive language). For each picture card, the researcher asked the child to identify three of the six vocabulary words in English and the other three in Spanish, giving no feedback. The researcher video recorded the testing and recorded the child's responses on a score sheet (see Appendix A for a sample score sheet). The videos 
were later reviewed for accuracy. Time taken to answer after the researcher prompted the child was also calculated from the video recordings.

Learning context. The researcher conducted the Spanish activities within the regularly scheduled center rotation time, usually lasting 45-60 minutes. During the center rotation, the researcher completed the same activity three to five times, while children were coming and going. When arriving to Nursery School, children first complete their Play Plans, a short writing and drawing task, that helps them solidify their pretend roles for socio-dramatic play. Centers begin after children are engaged in free-play for around an hour. Center rotation allows the children to look at a contract, which visually displays the center choices for the day, allowing each child to choose which center to go to and in which order. Children may travel from center to center individually and at their own pace or with a center buddy, typically another child with whom they may not regularly play. Purposively choosing a child's center buddy is used as a method to make new social connections, expanding everyone’s friendships within the Nursery School environment. There are generally between one and four children at a center at one time. For the purpose of this study, the six participants were paired with another child in the study and brought to the Spanish center to complete the activity. On some days, depending if a child was absent or still engaged in another center, the other child completed the activity individually with the researcher. All children in the study were paired with each other at least once, except for April and Sara; all children had at least one individual session except Lynne.

Learning activities. The study took place over eight weeks: one week pre-test, one week baseline, five weeks of intervention, and one week post-test. Spanning the five- 
week intervention period, the researcher was at Nursery School three days a week, for 45 minutes to an hour; this is the allotted time for daily center rotations. During this time frame, the researcher conducted the planned Spanish activities with all children who wanted to participate, as it was be presented on the children's daily contract. Video recordings and data were collected on only the six consented participants, however; all parents had signed a media release during initial enrollment at Nursery School. Children were not at the Spanish center for the entire duration of centers, as all children flowed in and out based on their personal choice of which centers to visit and when. This is the normal procedure for children at the Nursery School, as recommended by the National Association for the Education of Young Children (NAEYC), in concurrence with DAP (NAEYC, 2009). The six children participating, however, were encouraged to remain at the Spanish center until the activity was completed, generally lasting about 10 minutes; all of the children complied with this. Again, children typically moved from center to center with their center buddy, chosen by convenience based on the six consented participants. This made it easier for the researcher to video record the activities on only the children participating in the study.

Throughout the intervention, the participants learned words from five themes, each with five common vocabulary words, typically already known by preschoolers in their native language. Themes included: family (baseline), numbers, colors, body parts, household, and food (see Table 1 for the complete list of vocabulary words). The activities were designed to incorporate modeling, leading, repetition, and testing (not in the typical sense of the word, but more of a recall and practice manner). These components of direct instruction worked well and could naturally be embedded into the 
activities, while still engaging the children with the researcher, each other, and in their own self-motivation for learning.

The learning activities for the lessons implemented the direct instruction technique and were a mix of English and Spanish. During these activities, individuals or small groups (typically two children) came and went to the researcher's Spanish center. At this center, the researcher had hands-on, interactive activities that engaged the children in various means of representation for both English and Spanish, in visual (pictures and words) and audible manners (see Appendix B for an example of a lesson plan). The activities were designed so the researcher was able to interact with the children and provide examples and connections in both English and Spanish, allowing the children to interact with each other, ask questions, and practice the vocabulary.

All children at Nursery School were able to attend and participate in the Spanish center; the six selected children were specifically brought to the center to ensure participation. The children and researcher played using materials designated for that theme and specific activity, practicing the use of the learned Spanish words. Feedback and praise were given to each child for pronunciation and use of the Spanish words, with corrections given for mispronunciation.

Data collection and scoring procedures. Data collection based on the activities was broken down into trials, in which the researcher prompted the children in English or Spanish to practice pronunciation of the Spanish vocabulary words. One complete trial included a prompt by the researcher (and sometimes by a child), a response by a child, and feedback by the researcher. If a child responded, they were scored on pronunciation and use. If there was no response, the child automatically was scored 0 . Trials could be 
initiated by the researcher's prompts (Levels 1, 2, 3, and 4) or another child's independent use (Level 5); pronunciation and use were scored for any level of prompting. Table 2 provides definitions and examples for the five prompt levels, use, feedback, and what constituted a trial. Appendix C provides a blank data sheet used when scoring video recordings of the activities.

During intervention, the researcher collected data on each child's correct pronunciation and use of the learned Spanish vocabulary words. To do so, daily Spanish activities were video-recorded and later reviewed by the researcher and a trained assistant. Pronunciation and use were recorded from the videos using score sheets (see Appendix C) for each session the child was present. The reviewers counted the number of correct pronunciations and usage, as well as prompt levels and feedback or praise, recording the child's verbal pronunciation and actions.

Full credit for correct pronunciation and use was scored 2, while partial credit (mispronunciation) was scored 1, and no response (not speaking or using the word) was scored 0 . The researcher and assistant reviewed videos together to reach agreement on definition of correct pronunciation and use, along with prompt level and feedback or praise. The researcher and assistant jointly coded all videos, reaching consensus on each data point.

\section{Research Questions}

It was predicted that the six children would learn the Spanish words when linked to familiar English vocabulary through hands-on and engaging activities, using the direct instruction technique. The recall and retention of the words was predicted to be higher if a child used them in a peer-group environment during activities. Research Question 1 
asked whether there would be a significant improvement in correctly identified Spanish vocabulary words from pre-test to post-test, after the five-week intervention of engaging, hands-on, direct instruction activities were completed. Research Question 2 asked whether the children would learn and use the Spanish words, introduced within the direct instruction intervention, themed for each week, as evident from single-subject data displays. In addition to these specific questions, it was of interest to note whether direct instruction has a place in a developmentally appropriate preschool classroom. 


\section{CHAPTER IV}

\section{Results}

\section{Intervention Fidelity}

An important measure of intervention fidelity is the percentage of trials on which the researcher gave feedback to the participants, either as correction, example, or praise. Overall, $80 \%$ of the 1,656 trials included feedback from the researcher. However, the percentage of trials with feedback varied by the theme: (a) Numbers averaged $50.7 \%$ (range 46.3-53.5\%), (b) Colors averaged 84.6\% (range 70.2-98.4\%), (c) Body Parts averaged 92.5\% (range 89.2-94.7\%), (d) Household Items averaged 94.0\% (range 89.098.0\%), and (e) Food averaged 93.8\% (range 80.0-100.0\%). Although the overall percentage of trials with feedback was more than acceptable, there was a clear difference between Numbers and the other themes due to the number of successive trials in a row, such as counting, without interrupting to give feedback each time (e.g., "Uno, dos, tres, cuatro, cinco,” “Good job!”).

As verification that the participants did not receive dramatically different numbers of trials, the mean number of trials that each child received was calculated across all their days of participation. Three of the participants, Lynne, Ethan, and Thad, missed one activity each and April missed two activities over the course of the five-week intervention. Four of the participants had a very similar mean number of trials per activity, with April receiving a mean of 32.1, Lynne receiving a mean of 33.6, Cole receiving a mean of 32.6, and Ethan receiving a mean of 32.9. Sara and Thad, however, received a mean of 41.9 and 41.4 trials per activity, respectively, because on two days that they were partnered (Numbers, Day 3 and Colors, Day 1), the number of trials 
exceeded 70 (see Table 3). The duration of each activity with each child, the number of trials, and the number of seconds per trial (s/t) were determined and are displayed in Table 3. The length of activities ranged from just under 5 minutes to just over 15 minutes. The mean number of seconds that each trial took to complete ranged from 5.8 to 36.2 seconds, with Activity 3 for Numbers taking less time due to sequential counting during Uno, and Activity 3 for Body Parts taking the most time due to creating their own Mr. Potato Head and talking more casually than during other activities.

\section{Analysis of Individual Participants}

For each of the six participants, two graphs were created for each of the five themes, one for pronunciation score and another for prompt level (a total of 10 graphs per participant, Figures 2a through $7 \mathrm{j}$ ). Data from each of the three activities for each theme were cumulatively graphed across the number of trials for that activity, with a limit of 40 trials graphed per activity as most sessions did not exceed 40 trials. Cumulative graphs for pronunciation of Spanish words on each trial were created by adding the scores $(0,1$, 2) on each trial to the total score of the preceding trials in that activity. This method of graphing allows for easy visual inspection of a child's progress on pronunciation each day and across the week. Steeper slopes indicate more accurate pronunciation and flat slopes indicate trials with no response. A “perfect line” is included to provide a visual representation against which to base the child's performance; “perfect” would be receiving a pronunciation score of 2 on all trials. Generally, it was expected that performance over each successive day within a theme would move closer and closer to the "perfect line."

Similarly, cumulative graphs for the prompt level needed to elicit a response on a 
trial were created by adding the scores $(0,1,2,3,4,5)$ on each trial to the total score of the preceding trials in that activity. This method of graphing allows for easy visual inspection of the change in prompt level needed on each day and across the week. Steeper slopes indicate more independence (Levels 4 and 5) and flat slopes indicate trials with no response from the child. Use (verbal and non-verbal) was also included in the cumulative graphing of prompt level if the child did not already receive credit for pronunciation. A "perfect line" is included to provide a visual representation against which to base the child's performance; “perfect” would be receiving a prompt level score of 4 on all trials. As with pronunciation, it was expected that performance over each successive day within a theme would move closer and closer to the "perfect line."

April. Figures 2a through 2j provide the cumulative pronunciation and prompt level graphs across the five themes for April. Figure 2a shows that April's cumulative pronunciation scores for the Numbers theme were higher on Day 3 than Day 1, with Day 2 somewhat higher than the other two days. The slopes for all three days indicate consistently good pronunciation, except for brief breaks in the middle of the sessions, likely influenced by more interaction between the other child and researcher on those trials. Figure 2b shows a higher level of independence on Days 2 and 3 than Day 1. For the Colors theme, April's level of pronunciation was better on Day 1 than Day 2 (Figure 2c), while the level of prompting needed was similar on both days (Figure 2d). The same performance for pronunciation and prompt level is seen in Figures 2e and $2 \mathrm{f}$ for the Body Parts theme.

The graphs for the Household theme show more of the expected performance, with better pronunciation on Day 3 than Days 1 and 2 (Figure 2g) and more independence on 
Days 2 and 3 than one Day 1 (Figure 2h). The same pattern of improving pronunciation and independence is seen in Figures $2 \mathrm{i}$ and $2 \mathrm{j}$ for the Food theme. Overall, April showed improving performance in pronunciation and prompt level needed to elicit a response. The exception to that more general trend was with the Colors and Body Parts themes. Potentially, Day 3 could have shown higher performance, but April was absent on Day 3 for both of these themes.

Lynne. Figures 3a through 3j provide the cumulative pronunciation and prompt level graphs across the five themes for Lynne. Although Lynne’s pronunciation scores improved over three days for the Numbers theme (Figure 3a), her overall level was moderate, with no steep slopes. Similarly, she did not show a strong trend toward increasing independence for prompt level (Figure 3b), needing somewhat more prompting on Day 3. Lynne did much better, however, with the Colors theme, showing a high level of performance for pronunciation (Figure 3c) and prompt level (Figure 3d) on Day 2 as compared to Day 1. A pattern similar to the Numbers theme was evident for both Body Parts and Household themes in that there were no clear improvements in pronunciation (Figures 3e and 3g) and prompting (Figures $3 \mathrm{f}$ and $3 \mathrm{~h}$ ) across the three days for these themes.

On the Food theme, Lynne showed more of the expected pattern of results with higher performance on pronunciation (Figure 3i) and independence of prompt level (Figure 3j) on Day 3 than Days 1 and 2. Overall, Lynne’s performance somewhat fit the expected pattern of results for Colors and Body Parts. She otherwise showed a similar moderate level of performance across days for the other three themes.

Sara. Figures 4a through 4j provide the cumulative pronunciation and prompt level 
graphs across the five themes for Sara. For the Numbers theme, pronunciation (Figure 4a) and prompt level (Figure 4b) were higher on Day 2 than Days 1 and 3. The slopes on Day 2 for both graphs are also steeper than the slopes on Days 1 and 3, showing better pronunciation and more independence. Pronunciation (Figure 4c) for Sara on Day 1 of Colors demonstrates the attainment of the "perfect line.” Days 2 and 3 fall below this, but are following a very similar slope. Figure 4d, however, shows Sara's prompt levels were similar for all three days, but Day 1 is still higher than the other days. Another example of the expected pattern of results is the Body Parts theme for Sara. Day 3 was higher for both pronunciation (Figure 4e) and prompt level (Figure 4f) than Days 1 and 2. The slopes for these days are relatively similar, but the slope of Day 3 is somewhat steeper than the other two days.

Sara's results for pronunciation and prompt level for the Household theme (Figures 4g and 4h) show steep slopes on all three days across both graphs, with Day 2 lower overall than Days 1 and 3. Most days on both graphs are also closely following the "perfect line," except for Day 2 of pronunciation. For the Food theme, Day 1 shows a steeper slope and is higher than Days 2 and 3 (Figure 4i). On prompt level (Figure 4j), however, Day 3 is higher than Days 1 and 2, which follow a similar slope. Overall, Sara's performance on the Colors, Body Parts, and Household themes follows the expected pattern of results and also runs parallel to the "perfect line.” The other themes show no consistency in increasing pronunciation or prompt level, as Day 2 of Numbers is higher on both graphs than the other days, and Day 1 is higher on pronunciation for Food, but Day 3 is higher for prompt level.

Cole. Figures 5a through 5j provide the cumulative pronunciation and prompt level 
graphs across the five themes for Cole. Cole's performance on pronunciation and prompt level (Figures 5a and 5b) of the Numbers theme were similar, with Day 2 being higher than both Days 1 and 3. Moderate slopes were shown. For all three days of Colors on both pronunciation and prompt level (Figures 5c and 5d), performance closely paralleled each other, with no difference among the three days for pronunciation; however, independence for Day 3 in the second half of the activity was higher than Days 1 and 2. Performance on the Body Parts theme follows the expected pattern of results, with an increasing slope over Days 1, 2, and 3 for both pronunciation (Figure 5e) and prompt level (Figure 5f).

Performance on the Household theme shows similar patterns for all three days, with Day 3 being slightly higher than the other two days for pronunciation (Figure $5 g$ ). For prompt level, Days 2 and 3 are overlapping and are also higher than Day 1 (Figure 5h). Figures 5i and 5j for Cole show very little difference or increase in performance and a lower slope than most other themes. Overall, Cole showed little improvement over the days within each theme, with the exception of the Body Parts theme, which did follow the expected pattern of results.

Ethan. Figures 6a through 6j provide the cumulative pronunciation and prompt level graphs across the five themes for Ethan. Pronunciation and prompt level for the Numbers theme are undifferentiated in Figures 6a and 6b. Colors, however, followed the expected pattern of results for both pronunciation and prompt level (Figures 6c and 6d), with prompts on Day 3 surpassing the "perfect line” due to independent use (score of 5) of previously learned number words at the beginning of the activity. Pronunciation (Figure 6e) and prompt level (Figure 6f) for Body Parts also met the expected pattern of 
results, with Day 2 being higher than Day 1, which showed a fairly flat slope. Ethan's pronunciation (Figure 6g) and prompt level (Figure 6h) for the Household theme reverse, rather than follow, the expected pattern of results with Day 3 being lower than both Days 1 and 2. For the Food theme, Days 1 and 3 were slightly higher than Day 2 for pronunciation (Figure 6i) and overlapped each other. For prompt level, in Figure 6j, all three days overlap, showing a steady, moderate slope. Overall, Ethan's performance on pronunciation and independence or prompt level shows little consistency as the progress on each theme switches from week to week. For example, Colors and Body Parts followed the expected pattern of results, but Numbers and Household reversed that pattern.

Thad. Figures $7 \mathrm{a}$ through $7 \mathrm{j}$ provide the cumulative pronunciation and prompt level graphs across the five themes for Thad. Both improved pronunciation and increased independence for Thad were evident, in the expected pattern for Days 1, 2, and 3 of Numbers (Figures 7a and 7b), as Day 3 was higher than both Days 1 and 2. Day 1 of pronunciation for Colors (Figure 7c) followed the "perfect line" then plateaued about half way through the activity, resting lower than Day 3, but slightly higher than Day 2. Day 1 of prompt level (Figure 7d) shows a similar plateau; however, Days 2 and 3 intertwine at a higher point than Day 1, showing similar progress for those days. Days 1 and 3 of pronunciation for Body Parts (Figure 7e) show a steeper slope, parallel to the "perfect line," but leveling off toward the end of the activity. On the other hand, Day 2 shows moderate improvement at a slower rate and plateauing off about half way through the activity. Day 3 of prompt level shows more independence than Days 1 and 2 in Figure 7f; there is little difference between Days 1 and 2 for Body Parts. 
Days 2 and 3 of the Household theme show little difference for both pronunciation and prompt level in Figures $7 \mathrm{~g}$ and $7 \mathrm{~h}$. Thad's pronunciation (Figure 7i) for the Food theme is slightly higher than the prompt level (Figure 7j), but all three days on both graphs do not show much difference in the progress that was made. Overall, Thad showed minimal progress or differentiation, with the exception of the Numbers theme, which did follow the expected pattern of results.

\section{Trials with Use}

In addition to analyzing pronunciation and prompt level, trials were scored for use as a 0 or a 2, with a description of the motion or verbalization noted as reference to the use. Use is defined in Table 2, as demonstrating knowledge of a word (verbally or nonverbally) by various forms of identification. Figure 8 displays the percentage of the total number of trials on which each child was scored as demonstrating use of the vocabulary words. On average, $14.0 \%$ of the trials, across children, included use, ranging from $9.8 \%$ for Cole and Thad, to $21.7 \%$ for Sara. Figure 9 breaks down the trials with use into the prompt level after which they occurred. An average of $68.1 \%$ of the trials with use occurred in response to a Level 4 prompt (range 46.3-75.0\%). An average of 23.7\% of the trials occurred in response to a Level 5 prompt, which is independence (range 10.750.0\%). As can be seen in Figure 9, Sara differed from the other five children in that her usage trials were split between Level 4 and 5 prompts, while the other children primarily had use in response to a Level 4 prompt.

\section{Pre-Test and Post-Test}

The pre-test and post-test consisted of five picture cards, each with six pictures. The children were to point to the picture corresponding to the English or Spanish word spoken 
by the researcher; three words were presented in English and three in Spanish for each picture card. As can be determined from the data displayed in Table 4, the children correctly identified a mean of 14 English words (range 12-15) on the pre-test, with all 15 correct on the post-test. For the Spanish words, the children had a mean of 4.7 words (range 3-7) correct on the pre-test and a mean of 8.3 words (range 3-12) correct on the post-test. All of the girls showed clear improvement in the number of Spanish words learned from pre-test to post-test, doubling or tripling the number of words they identified correctly. Two of the boys (Cole and Ethan) essentially showed no change in words learned, while Thad showed a small improvement.

Due to the small sample size $(n=6)$, the Wilcoxin Signed Rank Test, a nonparametric statistic for small samples, was used to compare pre-test and post-test scores. There was a statistically significant increase in the number of Spanish words correctly identified from pre-test $(M=4.7)$ to post-test $(M=8.3), W=1.5, p<.05$ (one-tailed, critical value for $n=6$ is $W=2$ ). In addition to looking at correct answers, the time it took to provide an answer (i.e., fluency) was also calculated (again, see Table 4). At pretest, identifying Spanish words (whether correct, $M=4.3 \mathrm{~s}$, or incorrect, $M=3.7 \mathrm{~s}$ ) took significantly longer than identifying English words correctly $(M=1.8 \mathrm{~s}), W=1, p<.05$. At post-test, English words identified correctly $(M=1.0 \mathrm{~s})$ still took less time than identifying Spanish words correctly $(M=1.7 \mathrm{~s}), W=1, p<.05$; however, identifying Spanish words correctly took less time than when the wrong answer was selected $(M=$ $4.8 \mathrm{~s}), W=1, p<.05$. Lastly, identifying correct Spanish words took significantly less time at post-test $(M=1.7 \mathrm{~s})$ than at pre-test $(M=4.3 \mathrm{~s}), W=0, p<.05$.

As a last step in the descriptive analysis of these data, Table 5 displays each 
child's correct responses for each themed Spanish word on the pre- and post-tests. The last line labeled "Total” describes the total words correct on pre- and post-tests, as well as indicating how many words on the post-test were also correctly identified on the pre-test; this value is in the parentheses. 


\section{CHAPTER V}

\section{Discussion}

It was predicted that the children would retain and use Spanish words when presented with familiar English vocabulary through engaging, hands-on activities in a direct instruction format. The first research question asked whether there would be a statistically significant improvement in Spanish vocabulary (number of correctly identified words) from pre-test to post-test. It was evident from the pre-test and post-test comparison that there was an overall statistically significant increase in the number of words that the six children correctly identified. It is also clear that the three girls, April, Lynne, and Sara, showed the greatest improvements. Two of the boys, Cole and Thad, showed a small improvement, and one, Ethan, showed no improvement on the post-test. Despite this unexpected variation by gender in the number of Spanish words correctly identified on the post-test, all children improved on a measure of fluency, that being the time it took to identify each Spanish word correctly.

The second research question asked whether it would be evident from singlesubject data displays that the children in the study would learn and use the themed Spanish words each week. The expected pattern of results for the single-subject data was to see improved pronunciation and increased independence from prompts (Levels 4 and 5) over the three days of activities within each theme. Approximately one-third of the single-subject displays supported this expected pattern. More often, two or three of the activities within a theme were overlapping, similar in slope, and undifferentiated from each other.

An original design consideration was to have two days of teaching vocabulary 
words and one day of generalization to play activities. This would have allowed evaluation of whether the children were pronouncing and using the words independently. In lieu of this, data were collected on the number of trials during which the children used the themed words in some manner, such as repeating, pointing, or asking questions about the words. The data indicated that all children used the words in some manner on about $15 \%$ of trials with about two-thirds of those being in response to Level 4 prompts (e.g., “What is the Spanish word for leg?” or "Show me mano.”). On about one-third of the trials, such use was independent (Level 5), that is without any prompting by the researcher. For one subject, Sara, a little over $20 \%$ of the trials included use, with about half being independent. This use of the themed words was not prompted or trained; as such, it provides evidence of the children generalizing their newly acquired vocabulary. Overall, these findings support the use of direct instruction of Spanish vocabulary within the unique preschool setting of the West Virginia University Nursery School. Not only were improvements in pronunciation and independence noted, the children demonstrated usage of the vocabulary words without this being directly taught. It was also shown that even when there were not large increases in the number of vocabulary words known, all children were more fluent after the five weeks of direct instruction, in that they identified the correct words more quickly than incorrect words on pre- or posttest. It is notable that the three girls performed at a much higher level than the three boys. This result might have been expected, given that girls generally score higher on tests of language and communicative skills than do boys at this age and younger, as well as throughout the school years (Burman, Bitan, \& Booth, 2008; Huttenlocher, Haight, Bryk, Seltzer, \& Lyons, 1991). Of anecdotal interest, two of the girls (April and Sara) would 
correct the pronunciation of their center buddies, particularly the boys (e.g., "It's not pronounced que-sa, it’s que-soooooo.”).

\section{Limitations and Future Directions}

As in any research study, limitations present themselves as an afterthought to the intervention or were considered, but unattainable during the intervention. With this study, one of the first, and possibly most important, limitations is the small number of participants. For single-subject research, this number is generally acceptable, but to generalize to the wider population of preschool children, this study would have to be replicated with more participants and in other settings, both regionally and educationally. The West Virginia University Nursery School is a setting that holds education and the experiences involved in education to a very high esteem. Parents with children enrolled are all highly educated themselves and their children already have a "jump” on many components of preschool and kindergarten curricula.

Another limitation of this study was the pre- and post-tests. Originally, the pre- and post-tests were supposed to have opposite words, minimizing any practice effect in the test-retest. Distracter pictures would have been beneficial for the pre- and post-tests because during intervention, a few children would notice pictures they had not identified, but were prompted in Spanish and chose an incorrect picture. Also, it was noticeable that some children were keeping track of pictures they had or had not identified, so one or two distracters would account for using a process of elimination.

Another limitation during the study was with the video recordings. At some points, it was difficult to see the faces of the children to determine which child was saying what. There were also technological issues with the memory on the video camera, so some 
videos were recorded on the researcher's cell phone, where camera angle was also an issue. During Week 6, the Household Items theme, the camera was bumped by another child not participating in the study and fell to the ground. The fall made the recording blurry. The researcher and trained assistant had to rely on knowing the children's voices and the dialogue between the researcher and children to score them on pronunciation and use. These videos were viewed multiple times and voice clips were replayed to determine what was happening during the activity. No data was lost due to these technological setbacks.

It would be useful in future studies to do an initial general language assessment to evaluate proficiency in English vocabulary to establish a baseline level that might be predictive of how well children would then acquire Spanish vocabulary. This would be particularly useful when comparing girls and boys and could help explain the gender differences seen in this study. Burman et al. (2008) noted that females perform better on language tasks than males, even in children as young as two to three years of age. In their review, Burman et al. (2008) discussed that girls begin speaking at an earlier age, learn vocabulary at a faster rate, and have more spontaneous use of language. Depending on the study, these gender differences vary from small to moderate, but they are persistent from infancy through the school years. Burman and colleagues showed differences in pre-pubescent boys and girls in the areas of the brain that were activated during language tasks, with girls showing more general activation throughout the brain. Huttenlocher et al. (1991), however, suggested that the degree to which mothers talk with their children plays an important role in early language development; even so, the gender differences persist. Given these gender differences in early language learning, it would be important 
to also investigate how these differences show up in the acquisition of second language learning. The limited data here suggest easier learning of Spanish by the girls than the boys.

\section{Application in Preschool Education}

This research study, although single-subject, provides positive insight as to whether a combination of direct instruction, developmentally appropriate practices, hands-on and engaging activities, and peer interaction has a place in other preschool classrooms. From my perspective, the answer is most certainly yes. These components of education are adaptable within most classroom settings. Multiple times during the study, I found myself following the children's lead within activities, answering their questions, expanding on their statements, and allowing them to communicate with each other and even give feedback to each other, not necessarily focusing on the defined activity for the entire time. This is an important part of teaching because if the child is not interested and involved in the task at hand, it will show, which a few times it did. Instead, to engage the child and a peer or two, is to bring the instruction to their level, while supporting them enough to push them to the next level of learning and performance.

The learning environment at the West Virginia University Nursery School is certainly a unique and exceptional one. As many as 10 to 15 teachers, including observers, student teachers, and interns completing their practicum, are in the classroom at the same time on any given day. This is certainly not a "real world" setting when compared to how more typical preschools are staffed. However, the amount and degree of learning and interaction within the Nursery School is something that should be conducted in every classroom. In the classroom, and during this intervention, activities 
are set up for child exploration and engagement, not only with the materials, but with those involved in the activity as well, whether it be other children or an adult. Interaction and exploration are key for children to learn and maintain interest within an activity or long-term project; as such, following the child's lead and responding to their questions benefits all involved. For this research study, interactive activities where the children could be hands-on and fully participating in an activity, rather than rote learning or "drill and skill," where the child must respond multiple times in a row to "learn” the material, is more beneficial for learning. Allowing the child to not respond a few times and take in information in their own way, such as by listening to another child respond, lets them explore their own materials and understanding and make connections, pushing themselves to the next level of learning in an important way.

For this intervention, the activities were kept relatively short, although some lasted over the more typical five to ten minutes, based on child engagement in the activity. The activities were just long enough to obtain sufficient data and keep the child’s interest. However, at some points this was more difficult than others, as would be expected due to outside factors that the researcher was unable to control for, such as tiredness or events at home that might be affecting the child, their mood and attitude, and participation level. During this intervention, it was consequential to give as much feedback and praise as possible. This is because these frequent instances of feedback, whether in the form of correction, example, or praise, allowed the children to hear the word again, reflect on and adjust their pronunciation, as well as provide a "social reward" for the effort they were putting into the activity. Another way in which feedback and praise can motivate a child who may not be participating as much is in their hearing praise given to the other child in 
the dyad for answering correctly and then wanting that recognition as well. This can increase the motivation for the child to respond to the next prompt.

Although this intervention was set up in a free-play choice setting, there were multiple opportunities throughout the day to engage children in constructive play. Combined with a naturalistic approach, such as slipping various vocabulary word pairings in English and Spanish into a play and conversation could also benefit their learning. An example of this would be children playing in the dramatic play or housekeeping area where various vocabulary words for household items could easily be incorporated. In this context, instead of using pictures or drawings as in this study, the realistic play items would provide a visual representation that could be manipulated and actually used during play. Another example would be directing children with short phrases as to what they are supposed to be doing, such as washing their hands before lunch or snack. Combining the English phrase with the Spanish phrase, as well as doing hand-washing motions or pointing to the hand washing directions would allow the child to hear both linguistic forms of the directions, along with pairing the directive with visuals. These are just a couple of examples of many possible opportunities where Spanish vocabulary could be used and incorporated into the daily activities and routines of the preschool setting. The intensive intervention design of this study with multiple discrete trials per activity may not be practical for only one teacher and an aide in a typical preschool setting. However, as noted previously, prompting of vocabulary words and phrases in English and Spanish, along with use, throughout more naturalistic daily activities and routine would still be beneficial for learning. 


\section{Conclusion}

This study demonstrated the successful use of direct instruction, combined with engaging hands-on activities, in teaching Spanish vocabulary to preschool children. As such, it replicates similar work of Griva and Sivropoulou (2009) and further supports the usefulness of direct instruction (Ramirez \& Jones, 2012; Sibold, 2011) and active exploration (Jalongo \& Sobolak, 2011). There are some important limitations, but these are addressable with future research that will replicate and extend these findings.

Instruction not only occurs across domains for the child, but across settings, so extending their learning of a second language to the home would be beneficial for the child's overall learning experience. An example of this would be the Family Backpack Project (Rowe \& Fain, 2013), which extends literacy between home and school contexts and engages the parents in learning both languages as well, by listening to audio books in both languages and pulling out relevant vocabulary. Another similar project, the Bilingual Journaling Approach (Caesar \& Wolf Nelson, 2014), takes the lives of the learners and makes the simple events of their daily routine the activity material. At home, the parent and child are to describe what they did, such as going to the park or store, in their native language, again illustrating the events. Once at school, teachers work with the children to translate their personal stories into English, focusing on literacy and print knowledge.

With the number of Spanish speakers in the United States on the rise, education is likely to become increasingly bilingual, making it necessary to adapt their curriculum. The lessons learned in this study are applicable to teaching both English and Spanish to native English and native Spanish speakers. Direct instruction is a promising method for 
bilingual education beginning in the preschool classroom. Considering the children progressed greatly in pronunciation and independence over only a five-week period, for, on average, thirty minutes of instruction time per week, imagine what could be accomplished when incorporating second language instruction into a more naturalistic play environment, leisurely, interactively, and routinely. 


\section{References}

Alghamdi, R., \& Gillies, R. (2013). The impact of cooperative learning in comparison to traditional learning (small groups) on EFL learners’ outcomes when learning English as a foreign language. Asian Social Science, 9, 19-27.

Amir, A. (2013). Self-policing in the English as a foreign language class. Research on Youth and Language, 7, 84-105.

Barnett, W. S., Yarosz, D. J., Thomas, J., Jung, K., \& Blanco, D. (2007). Two-way and monolingual English immersion in preschool education: An experimental comparison. Early Childhood Research Quarterly, 22, 277-293.

Barnett, W. S., Carolan, M. E., Fitzgerald, J., \& Squires, J. H. (2012). The state of preschool: 2012. National Institute for Early Education Research. Retrieved Apr 10, 2014, from http://nieer.org/sites/nieer/files/yearbook2012.pdf

Birdsong, D. (2006) Age and second language acquisition and processing: A selective overview. Language Learning, 56, 9-49.

Burman, D. D., Bitan, T., \& Booth, J. R. (2008). Sex differences in neural processing of language among children. Neuropsychologia, 46, 1349-1362.

Caesar, L. G., \& Wolf Nelson, N. (2014). Parental involvement in language and literacy acquisition: A bilingual journaling approach. Child Language Teaching and Therapy, 30, 317-336.

Copple, C., \& Bredekamp, S. (Eds.). (2009). Developmentally appropriate practice in early childhood programs: Serving children from birth through age 8. National Association for the Education of Young Children: Washington, DC.

DeVito, M. C., Warash, B. G., Root, A. K., \& Curtis, R. (2013). Parents’ value of play in 
early childhood: A comparative study of spousal play beliefs. (Unpublished thesis manuscript). West Virginia University, Morgantown, WV.

Genesee, F. (2000). Brain research: Implications for second language learning. ERIC Clearinghouse on Languages and Linguistics. Retrieved Mar 31, 2014, from http://escholarship.org/uc/item/58n560k4

Goodrich, J. M., Lonigan, C. J., \& Farver, J. M. (2013). Do early literacy skills in children's first language promote development of skills in their second language? An experimental evaluation of transfer. Journal of Educational Psychology, 105, 414-426.

Greene, K. J., Peña, E. D., \& Bedore, L. M. (2012). Lexical choice and language selection in bilingual preschoolers. Child Language Teaching and Therapy, 29, 2739.

Griva, E., \& Sivropoulou, R. (2009). Implementation and evaluation of an early foreign language learning project in kindergarten. Early Childhood Education Journal, 37, 79-87.

Gürsoy, E., \& Akin, F. (2013). Is younger really better? Anxiety about learning a foreign language in Turkish children. Social Behavior and Personality, 41, 827-842.

Hummel, K. M. (2013). Target-language community involvement: Second-language linguistic self-confidence and other perceived benefits.

Huttenlocher, J., Haight, W., Bryk, A., Seltzer, M., \& Lyons, T. (1991). Early vocabulary growth: Relation to language input and gender. Developmental Psychology, 27, 236-248.

Jalongo, M. R., \& Sobolak, M. J. (2011). Supporting young children’s vocabulary 
growth: The challenges, the benefits, and evidence-based strategies. Early Childhood Education Journal, 38, 421-429.

Johnson, J. S., \& Newport, E. L. (1989). Critical period effects in second language learning: The influence of maturational state on the acquisition of English as a second language. Cognitive Psychology, 21, 60-99.

Language structure: You're born with it. (2014, April). Science Daily. Retrieved Apr 9, 2014, from http://www.sciencedaily.com/releases/2014/04/140408122316.htm? utm_source=feedburner\&utm_medium=email\&utm_campaign=Feed\%3A+science daily\%2Fmind_brain\%2Fchild_development+\%28Child+Development+News+— +ScienceDaily\%29

Miller, L. B., \& Dyer, J. L. (1971). Two kinds of kindergarten after four types of Head Start. (ERIC Document Reproduction Service Nos. ED 050824 and PS 004 760). National Association for the Education of Young Children. (2009). Developmentally appropriate practice in early childhood programs serving children from birth through age 8: A position statement of the National Association for the Education of Young Children. Retrieved Apr 7, 2014, from http://www.naeyc.org/files/naeyc/ file/positions/PSDAP.pdf

Neu, R. A. (2012). An exploration of oral language development in Spanish-speaking preschool students. Early Childhood Education Journal, 41, 211-218.

Philp, J., \& Tognini, R. (2009). Language acquisition in foreign language contexts and the differential benefits of interaction. International Review of Applied Linguistics in Language Teaching, 47, 245-266.

Porter, A., McMaken, J., Hwang, J., \& Yang, R. (2011). Common Core Standards: The 
new U.S. intended curriculum. Educational Research, 40, 103-116.

Pressley, M., Samuel, J., Hershey, M. M., Bishop, S. L., \& Dickinson, D. (1981). Use of a mnemonic technique to teach young children foreign language vocabulary. Contemporary Educational Psychology, 6, 110-116.

Ramirez, H., \& Jones, D. (2012). Effects of direct instruction and corrective feedback on second language acquisition. National Forum of Educational Administration and Supervision Journal, 30, 64-87.

Riley-Ayers, S., Garcia, J. S., Frede, E., \& Brenneman, K. (2011a). Early Learning Scale guidebook: Improving teaching through systematic assessment. National Institute for Early Education Research.

Riley-Ayers, S., Garcia, J. S., Frede, E., \& Brenneman, K. (2011b). Improving teaching through systematic assessment: Early Learning Scale guidebook. National Institute for Early Education Research.

Rowe, D., \& Fain, J. G. (2013). The Family Backpack Project: Responding to duallanguage texts through family journals. Language Arts, 90, 402-416.

Rowe, M. L., Silverman, R. D., \& Mullan, B. E. (2012). The role of pictures and gestures as nonverbal aids in preschoolers’ word learning in a novel language. Contemporary Educational Psychology, 38, 109-117.

San Diego County Office of Education. (n.d.). California common core state standards in Spanish language arts and literacy in history/social studies, science, and technical subjects. Retrieved 3 Aug, 2014, from http://commoncore-espanol.com/californiacommon-core-state-standards-spanish-language-arts-and-literacy-historysocialstudies 
Shin, H. B., \& Ortman, J. M. (2011). Language projections: 2010 to 2020. Retrieved 3 Apr, 2014, http://www.census.gov/hhes/socdemo/language/data/acs/Shin_Ortman_ FFC2011_paper.pdf

Sibold, C. (2011). Building English language learners’ academic vocabulary: Strategies and tips. Multicultural Education, 18, 24-28.

Snow, C. E., \& Hoefnagel-Höhle, M. (1978). The critical period for language acquisition: Evidence from second language learning. Child Development, 49, 1114-1128.

United States Census Bureau. (2012). Language spoken at home: 2012 American community survey 1-year estimates. Retrieved 20 Nov, 2013, from http://factfinder2.census.gov/faces/tableservices/jsf/pages/productview.xhtml? pid=ACS_12_1YR_S1601\&prodType=table

Wanzek, J. (2014). Building word knowledge: Opportunities for direct vocabulary instruction in general education for students with reading difficulties. Reading and Writing Quarterly: Overcoming Learning Difficulties, 30, 139-164.

Warash, B. G., Curtis, R., Hursh, D., \& Tucci, V. (2009). Skinner meets Piaget on the Reggio playground: Practical synthesis of Applied Behavior Analysis and Developmentally Appropriate Practice orientations. Journal of Research in Childhood Education, 22, 441-453.

West Virginia Department of Eduation. (2010). Early learning standards framework: Content standards and learning criteria for West Virginia pre-kindergarten (WV Pre-k). Retrieved 20 Nov, 2013, from http://wvde.state.wv.us/policies/p2520.15.pdf What Works Clearinghouse, US Department of Education. (2007, May 21). WWC intervention report: Direct instruction, DISTAR, and Language for Learning. 
(ERIC Document Reproduction Service No. ED 497 624).

Williamson, F. (1970). DISTAR reading: Research and experiment. (ERIC Document Reproduction Service Nos. ED 045318 and RE 003 163).

Yeung, S. S. S., Siegel, L. S., \& Chan, C. K. K. (2013). Effects of a phonological awareness program on English reading and spelling among Hong Kong Chinese ESL children. Reading and Writing: An Interdisciplinary Journal, 26, 681-704. 
Table 1

English and Spanish (in italics) Vocabulary Words for the Baseline Condition and the Five Themes

\begin{tabular}{cccccc}
\hline $\begin{array}{c}\text { Family } \\
\text { (Baseline) }\end{array}$ & Numbers & Colors & $\begin{array}{c}\text { Body } \\
\text { Parts }\end{array}$ & $\begin{array}{c}\text { Household } \\
\text { Items }\end{array}$ & Food \\
\hline mom & one & red & arm & house & milk \\
dad & two & pojo & brazo & casa & leche \\
& dos & rosa & cabeza & cama & pan \\
sister & three & green & eyes & table & cheese \\
& tres & verde & ojos & mesa & queso \\
baby & four & blue & leg & chair & meat \\
& cuatro & azul & pierna & silla & carne \\
& five & black & hand & bathroom & candy \\
& cinco & negro & mano & baño & dulce \\
& & & & &
\end{tabular}


Table 2

Definitions and Examples for Instructional Trial Terms

\begin{tabular}{|c|c|c|}
\hline Terms & Definitions & Examples \\
\hline One & Pairing the English and Spanish words together & "The Spanish word for one is uno." \\
\hline Two & Saying the Spanish word without pairing with the English word & “Can you say leche?” \\
\hline Three & Giving the starting sounds of the Spanish word & "What is the Spanish word for leg? P-p-pier-..." \\
\hline "Reverse” Four & Asking what the English word is for a Spanish word & “Can you point to queso?” \\
\hline Five & $\begin{array}{l}\text { Spontaneous, independent use of the Spanish word (no } \\
\text { prompting from researcher) }\end{array}$ & “That one is what? Cabeza.” (points) \\
\hline Use & $\begin{array}{l}\text { Demonstrating knowledge of the word by pointing to a picture, } \\
\text { pairing a word card and picture card, asking a question about } \\
\text { the word, correcting a classmate, independent use, or another } \\
\text { form of identification that may not be spoken }\end{array}$ & $\begin{array}{l}\text { Pointing to the correct picture when asked, “Can } \\
\text { you find a cama on the map?" or "What is mano } \\
\text { again?” }\end{array}$ \\
\hline Trial & $\begin{array}{l}\text { The full "cycle” of prompt, response (pronunciation and use), } \\
\text { and feedback and praise based around a Spanish word } \\
\text { *A trial could also emerge from the spontaneous word use of a } \\
\text { child } \\
\text { **Whether directed to an individual child or started by a child, } \\
\text { all participants have an equal opportunity to respond to the } \\
\text { prompt }\end{array}$ & $\begin{array}{l}\text { “This one is mano, can you say mano?” } \\
\text { "Mono...” } \\
\text { "Very close, maaaa-no.” } \\
\text { "Maaaa-no.” } \\
\text { "Great job! Mano is hand in Spanish.” }\end{array}$ \\
\hline
\end{tabular}


Table 3

Themes and Activities for Each Week, with the Times, Number of Trials, and Seconds per Trial (s/t) for Each Child

\begin{tabular}{|c|c|c|c|c|c|c|c|}
\hline Week and Words & Day and Activities & \multicolumn{6}{|c|}{ Child } \\
\hline Week 2: & 1. Roles of the Family Members & $6: 25 \mathrm{~m}$ & $6: 25 \mathrm{~m}$ & $4: 47 \mathrm{~m}$ & $6: 29 \mathrm{~m}$ & $4: 47 \mathrm{~m}$ & $6: 29 \mathrm{~m}$ \\
\hline & 3. Family Fill-In Book & $7: 35 \mathrm{~m}$ & (absent) & (absent) & (absent) & $8: 28 \mathrm{~m}$ & 7:03 m \\
\hline \multirow[t]{3}{*}{$\begin{array}{l}\text { Week 3: } \\
\text { Numbers }\end{array}$} & 1. Number Roll & $\begin{array}{c}8: 24 \mathrm{~m} \\
52 \text { trials } \\
9.7 \mathrm{~s} / \mathrm{t}\end{array}$ & $\begin{array}{c}5: 33 \mathrm{~m} \\
33 \text { trials } \\
10.1 \mathrm{~s} / \mathrm{t}\end{array}$ & $\begin{array}{c}7: 48 \mathrm{~m} \\
49 \text { trials } \\
9.6 \mathrm{~s} / \mathrm{t}\end{array}$ & $\begin{array}{c}5: 33 \mathrm{~m} \\
33 \text { trials } \\
10.1 \mathrm{~s} / \mathrm{t}\end{array}$ & $\begin{array}{c}8: 24 \mathrm{~m} \\
52 \text { trials } \\
9.7 \mathrm{~s} / \mathrm{t}\end{array}$ & $\begin{array}{c}7: 48 \mathrm{~m} \\
49 \text { trials } \\
9.6 \mathrm{~s} / \mathrm{t}\end{array}$ \\
\hline & 2. Pom-Pom Math & $\begin{array}{c}5: 37 \mathrm{~m} \\
21 \text { trials } \\
16.0 \mathrm{~s} / \mathrm{t}\end{array}$ & $\begin{array}{c}7: 47 \mathrm{~m} \\
41 \text { trials } \\
11.4 \mathrm{~s} / \mathrm{t}\end{array}$ & $\begin{array}{c}8: 05 \mathrm{~m} \\
41 \text { trials } \\
11.8 \mathrm{~s} / \mathrm{t}\end{array}$ & $\begin{array}{c}7: 01 \mathrm{~m} \\
41 \text { trials } \\
10.3 \mathrm{~s} / \mathrm{t}\end{array}$ & $\begin{array}{c}5: 30 \mathrm{~m} \\
34 \text { trials } \\
9.7 \mathrm{~s} / \mathrm{t}\end{array}$ & $\begin{array}{c}8: 05 \mathrm{~m} \\
41 \text { trials } \\
11.8 \mathrm{~s} / \mathrm{t}\end{array}$ \\
\hline & 3. Uno & $\begin{array}{c}5: 55 \mathrm{~m} \\
35 \text { trials } \\
10.1 \mathrm{~s} / \mathrm{t}\end{array}$ & $\begin{array}{c}5: 39 \mathrm{~m} \\
31 \text { trials } \\
12.9 \mathrm{~s} / \mathrm{t}\end{array}$ & $\begin{array}{c}6: 44 \mathrm{~m} \\
70 \text { trials } \\
5.8 \mathrm{~s} / \mathrm{t}\end{array}$ & $\begin{array}{c}5: 55 \\
35 \text { trials } \\
10.1 \mathrm{~s} / \mathrm{t}\end{array}$ & $\begin{array}{c}5: 39 \\
31 \text { trials } \\
12.9 \mathrm{~s} / \mathrm{t}\end{array}$ & $\begin{array}{c}6: 44 \mathrm{~m} \\
70 \text { trials } \\
5.8 \mathrm{~s} / \mathrm{t}\end{array}$ \\
\hline \multirow{2}{*}{$\begin{array}{l}\text { Week 4: } \\
\text { Colors }\end{array}$} & 2. Go Fish! & $\begin{array}{c}7: 48 \mathrm{~m} \\
39 \text { trials } \\
12.0 \mathrm{~s} / \mathrm{t}\end{array}$ & $\begin{array}{c}7: 30 \mathrm{~m} \\
23 \text { trials } \\
19.6 \mathrm{~s} / \mathrm{t}\end{array}$ & $\begin{array}{c}10: 35 \mathrm{~m} \\
49 \text { trials } \\
13.0 \mathrm{~s} / \mathrm{t}\end{array}$ & $\begin{array}{c}10: 35 \mathrm{~m} \\
49 \text { trials } \\
13.0 \mathrm{~s} / \mathrm{t}\end{array}$ & $\begin{array}{c}6: 25 \mathrm{~m} \\
32 \text { trials } \\
12.0 \mathrm{~s} / \mathrm{t}\end{array}$ & $\begin{array}{c}7: 48 \mathrm{~m} \\
39 \text { trials } \\
12.0 \mathrm{~s} / \mathrm{t}\end{array}$ \\
\hline & 3. Twister & (absent) & (absent) & $\begin{array}{c}5: 14 \mathrm{~m} \\
36 \text { trials } \\
8.7 \mathrm{~s} / \mathrm{t}\end{array}$ & $\begin{array}{c}5: 14 \mathrm{~m} \\
36 \text { trials } \\
8.7 \mathrm{~s} / \mathrm{t}\end{array}$ & $\begin{array}{c}5: 40 \mathrm{~m} \\
32 \text { trials } \\
10.6 \mathrm{~s} / \mathrm{t}\end{array}$ & $\begin{array}{c}5: 40 \mathrm{~m} \\
32 \text { trials } \\
10.6 \mathrm{~s} / \mathrm{t}\end{array}$ \\
\hline
\end{tabular}


Direct Instruction of Spanish 56

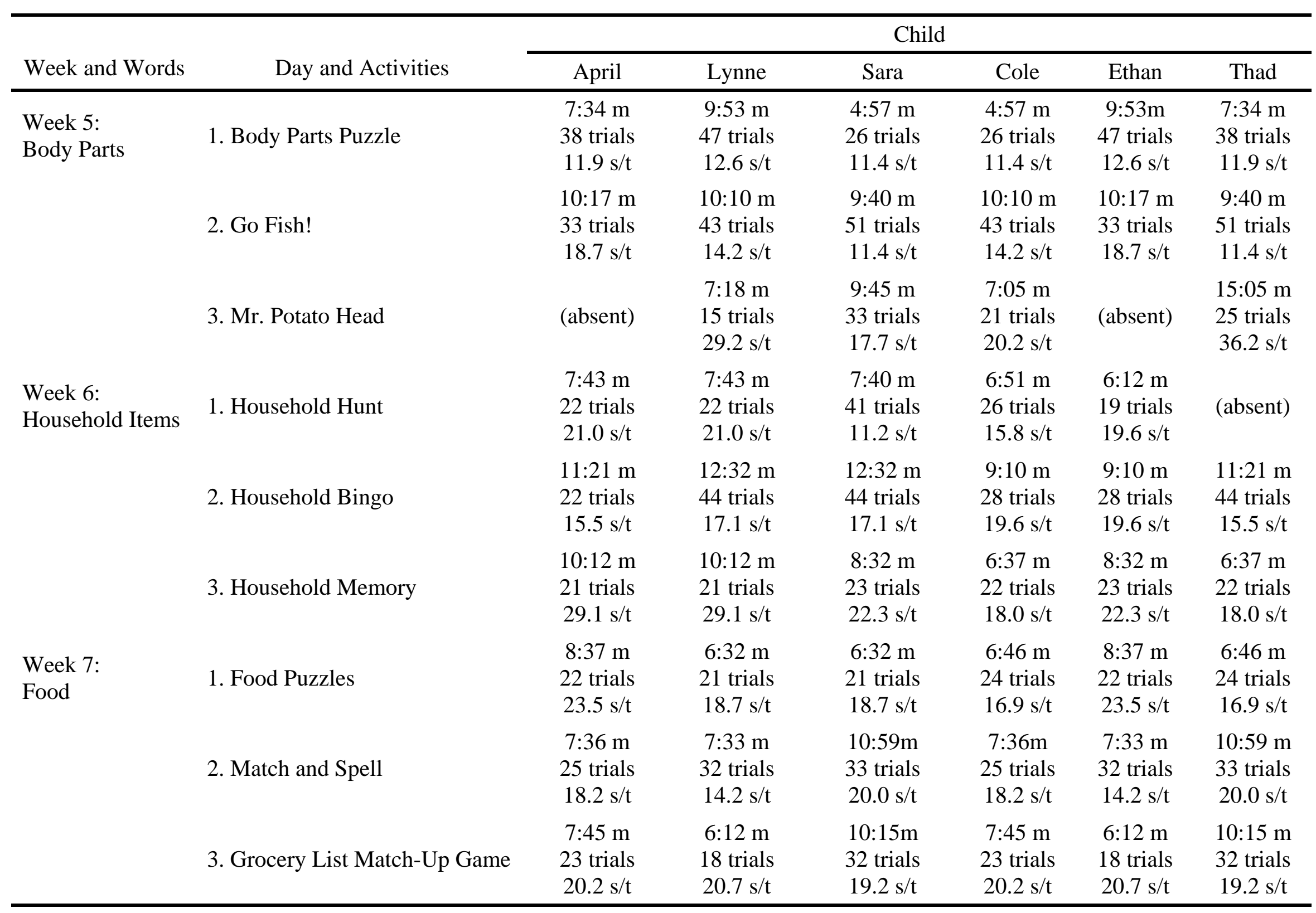




\section{Table 4}

Results from the Pre-Test and Post-Test of English and Spanish Vocabulary Words for the Six Children, Including Number of Correct and Incorrect Words, and Mean Time Taken to Select Correct and Incorrect Words

\begin{tabular}{|c|c|c|c|c|c|c|}
\hline \multirow[b]{2}{*}{ Testing (Pre and Post) } & \multicolumn{6}{|c|}{ Child } \\
\hline & April & Lynne & Sara & Cole & Ethan & Thad \\
\hline \multicolumn{7}{|l|}{ Pre-test } \\
\hline \multicolumn{7}{|l|}{ English words } \\
\hline Number of correct words & 15 & 13 & 14 & 12 & 15 & 15 \\
\hline Mean time: Correct words & $1.7 \mathrm{~s}$ & $2.2 \mathrm{~s}$ & $1.6 \mathrm{~s}$ & $2.3 \mathrm{~s}$ & $2.2 \mathrm{~s}$ & $1.1 \mathrm{~s}$ \\
\hline Mean time: Incorrect words & & $5.0 \mathrm{~s}$ & $2.0 \mathrm{~s}$ & $4.3 \mathrm{~s}$ & & \\
\hline \multicolumn{7}{|l|}{ Spanish words } \\
\hline Number of correct words & 6 & 3 & 3 & 5 & 4 & 7 \\
\hline Mean time: Correct words & $5.2 \mathrm{~s}$ & $3.3 \mathrm{~s}$ & $3.0 \mathrm{~s}$ & $2.0 \mathrm{~s}$ & $5.5 \mathrm{~s}$ & $6.9 \mathrm{~s}$ \\
\hline Mean time: Incorrect words & $3.4 \mathrm{~s}$ & $4.0 \mathrm{~s}$ & $3.5 \mathrm{~s}$ & $2.6 \mathrm{~s}$ & $4.4 \mathrm{~s}$ & $4.5 \mathrm{~s}$ \\
\hline \multicolumn{7}{|l|}{ Post-test } \\
\hline \multicolumn{7}{|l|}{ English words } \\
\hline Number of correct words & 15 & 15 & 15 & 15 & 15 & 15 \\
\hline Mean time: Correct words & $1.1 \mathrm{~s}$ & $1.1 \mathrm{~s}$ & $1.0 \mathrm{~s}$ & $1.1 \mathrm{~s}$ & $1.0 \mathrm{~s}$ & $1.0 \mathrm{~s}$ \\
\hline \multicolumn{7}{|l|}{ Mean time: Incorrect words } \\
\hline \multicolumn{7}{|l|}{ Spanish words } \\
\hline Number of correct words & 12 & 8 & 11 & 6 & 3 & 10 \\
\hline Mean time: Correct words & $2.0 \mathrm{~s}$ & $1.8 \mathrm{~s}$ & $2.1 \mathrm{~s}$ & $1.0 \mathrm{~s}$ & $1.3 \mathrm{~s}$ & $1.9 \mathrm{~s}$ \\
\hline Mean time: Incorrect words & $9.7 \mathrm{~s}$ & $3.7 \mathrm{~s}$ & $2.0 \mathrm{~s}$ & $1.9 \mathrm{~s}$ & $2.9 \mathrm{~s}$ & $8.8 \mathrm{~s}$ \\
\hline
\end{tabular}


Table 5

Correct Identification of Each English and Spanish Word on the Pre- and Post-Tests for Each Child

\begin{tabular}{|c|c|c|c|c|c|c|c|c|c|c|c|c|}
\hline \multirow[b]{2}{*}{ Words } & \multicolumn{2}{|c|}{ April } & \multicolumn{2}{|c|}{ Lynne } & \multicolumn{2}{|c|}{ Sara } & \multicolumn{2}{|c|}{ Cole } & \multicolumn{2}{|c|}{ Ethan } & \multicolumn{2}{|c|}{ Thad } \\
\hline & Pre & Post & Pre & Post & Pre & Post & Pre & Post & Pre & Post & Pre & Post \\
\hline Leche & $X$ & $X$ & & & $X$ & $X$ & & & $X$ & $X$ & $X$ & $X$ \\
\hline Cuatro & $X$ & $\mathrm{X}$ & & $X$ & & & & & & & & \\
\hline Pierna & $X$ & $\mathrm{X}$ & & & & & & & $X$ & & $X$ & $X$ \\
\hline Padre & $\mathrm{X}$ & & $X$ & $X$ & & $X$ & $X$ & & & & $X$ & $X$ \\
\hline Verde & & & $X$ & $\mathrm{X}$ & & & & $X$ & & & $\mathrm{X}$ & $\mathrm{X}$ \\
\hline Pan & & $\mathrm{X}$ & & $\mathrm{X}$ & & $\mathrm{X}$ & & & & $\mathrm{X}$ & $X$ & $X$ \\
\hline Uno & $\mathrm{X}$ & $X$ & & $X$ & & $\mathrm{X}$ & & & & & & \\
\hline Casa & $X$ & $\mathrm{X}$ & & & $X$ & & & $\mathrm{X}$ & $X$ & & & $\mathrm{X}$ \\
\hline Rosa & & $\mathrm{X}$ & & $\mathrm{X}$ & & $X$ & & $X$ & & $\mathrm{X}$ & $X$ & $X$ \\
\hline Negro & & $X$ & & $X$ & & $X$ & & & & & & \\
\hline Baño & & $\mathrm{X}$ & & & & $\mathrm{X}$ & & & & & & $\mathrm{X}$ \\
\hline Carne & & $X$ & & $X$ & & $X$ & $\mathrm{X}$ & $\mathrm{X}$ & $X$ & & $X$ & $X$ \\
\hline Rojo & & $X$ & & & $X$ & $X$ & $X$ & $X$ & & & & $X$ \\
\hline Mano & & & $X$ & & & $\mathrm{X}$ & $\mathrm{X}$ & & & & & \\
\hline Dulce & & $\mathrm{X}$ & & & & $X$ & $X$ & $\mathrm{X}$ & & & & \\
\hline Total & 6 & $\begin{array}{l}12 \\
(5)\end{array}$ & 3 & $\begin{array}{c}8 \\
(2)\end{array}$ & 3 & $\begin{array}{l}11 \\
(2)\end{array}$ & 5 & $\begin{array}{c}6 \\
(3)\end{array}$ & 4 & $\begin{array}{c}3 \\
(1)\end{array}$ & 7 & $\begin{array}{l}10 \\
(7)\end{array}$ \\
\hline
\end{tabular}

Note. For the Total, the values in parentheses indicate the number of words that were identified correctly on both the pre- and post-tests. 
Figure 1. Example of a pre- and post-test picture cards to assess receptive language in English and Spanish.

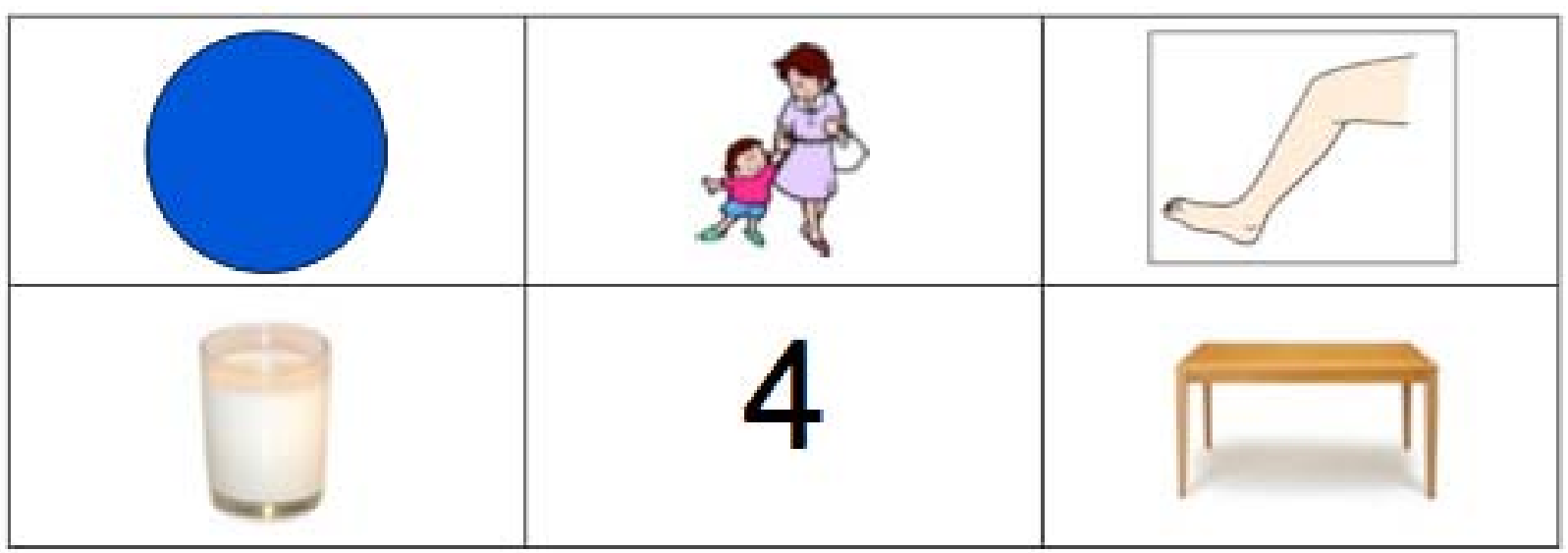



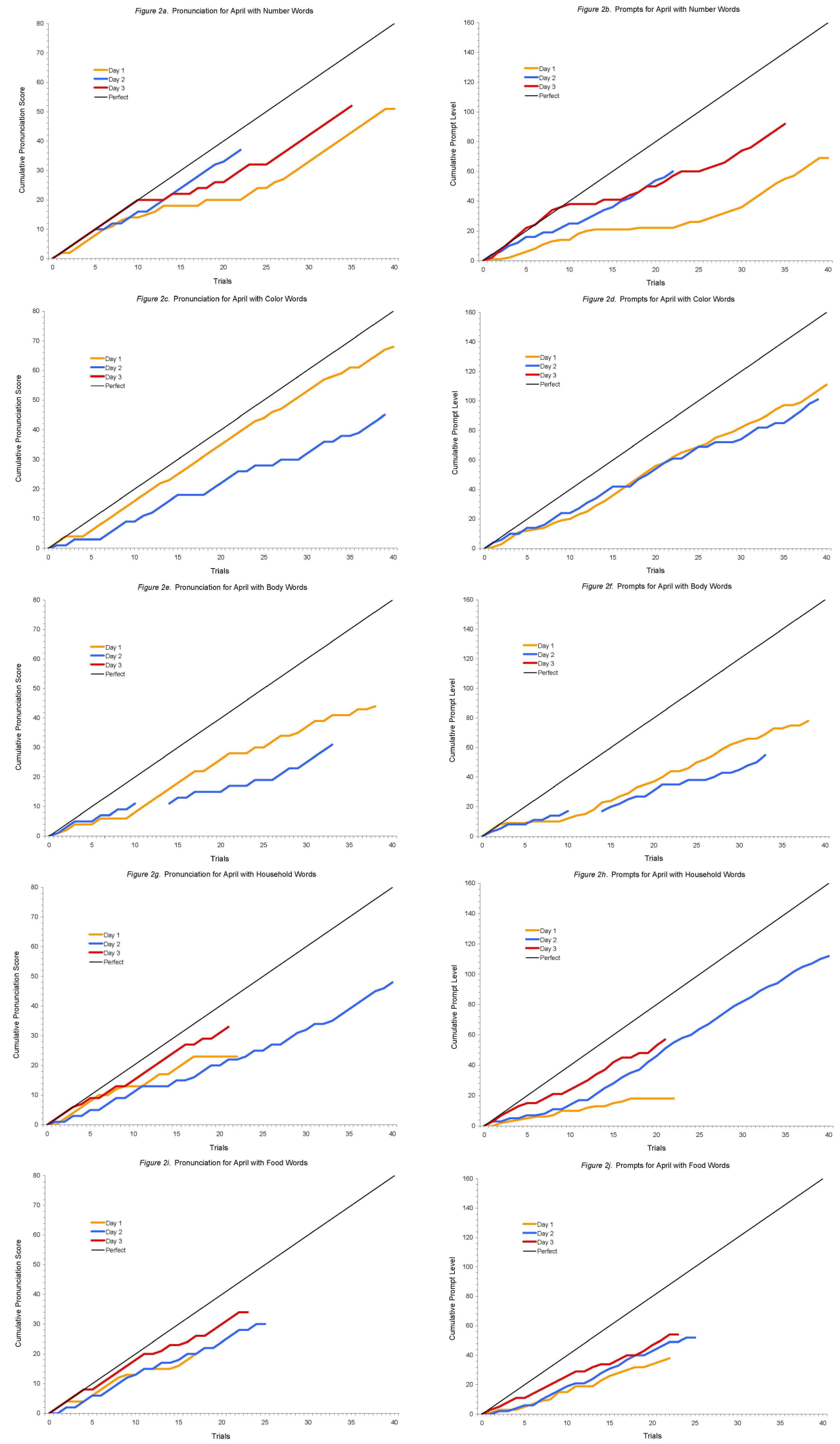
Direct Instruction of Spanish 61
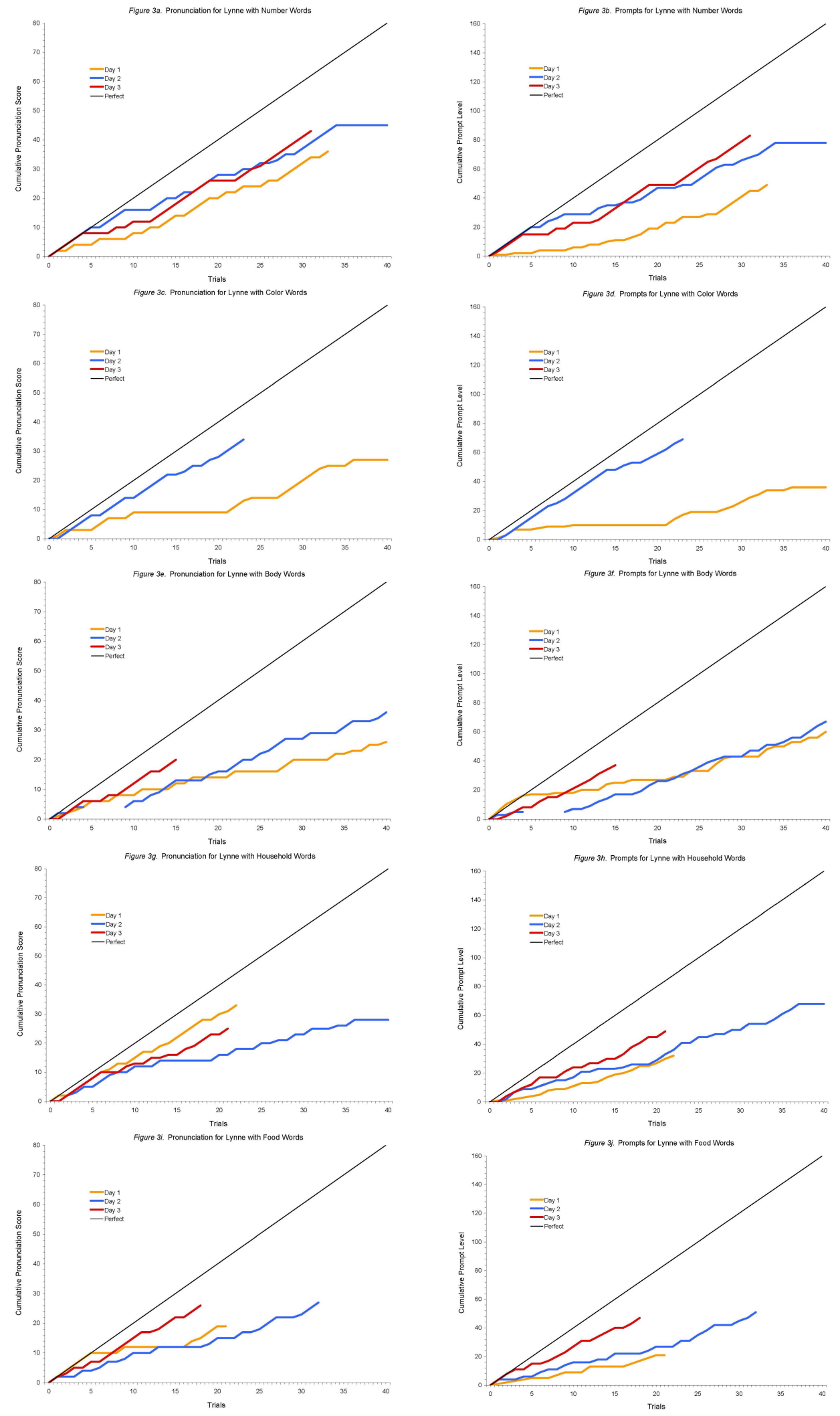
Direct Instruction of Spanish 62
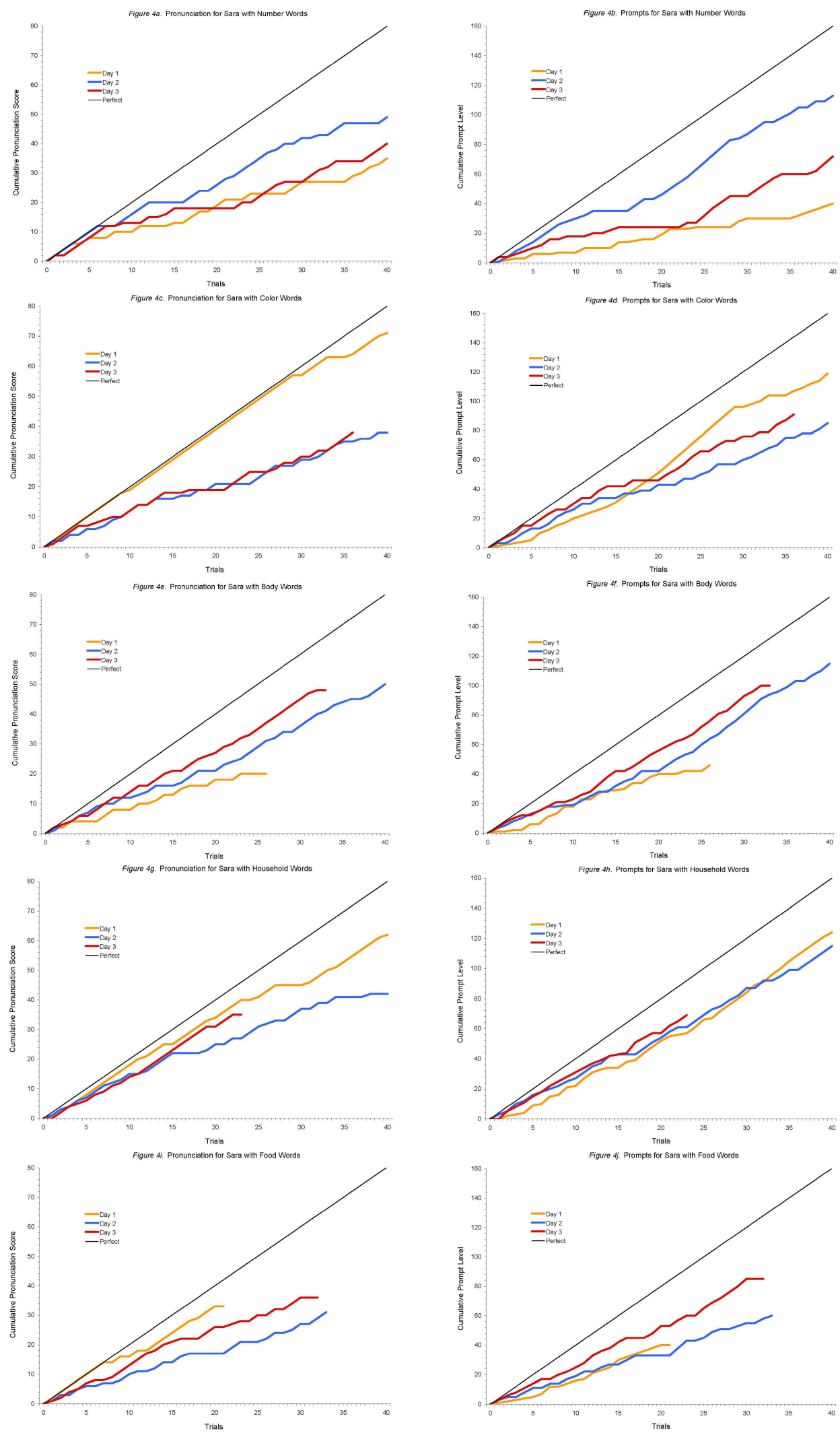
Direct Instruction of Spanish 63
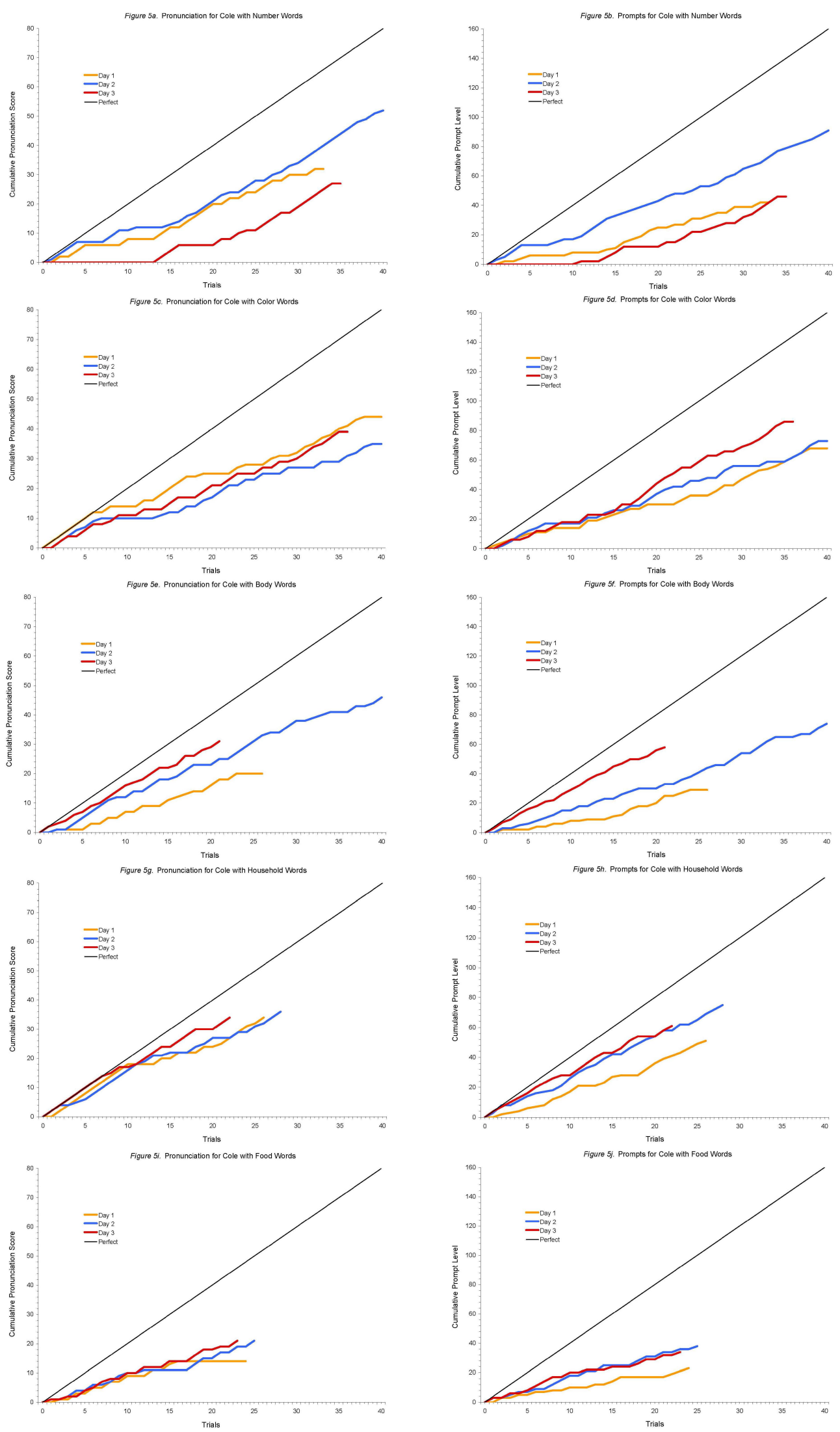
Direct Instruction of Spanish 64
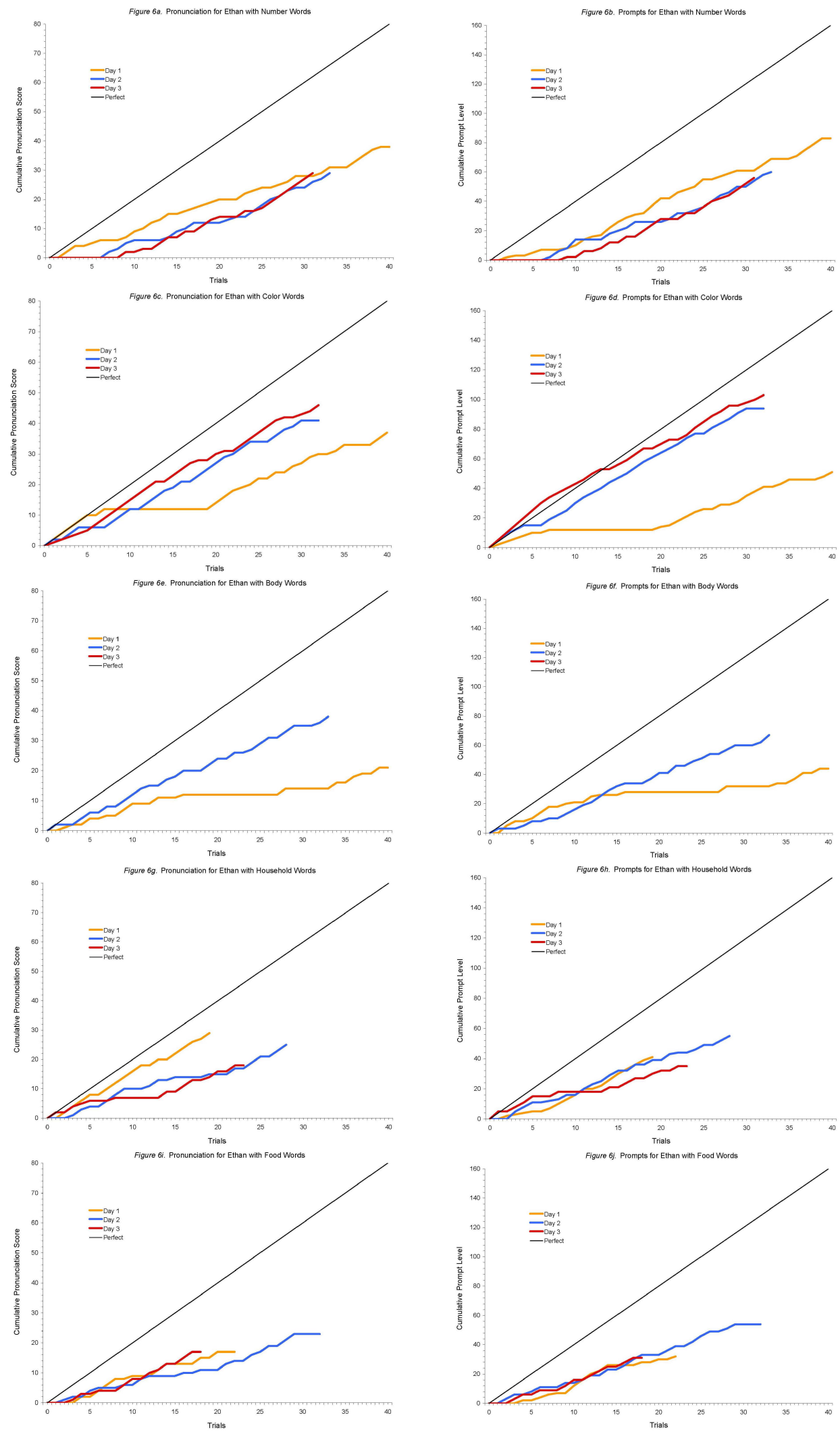

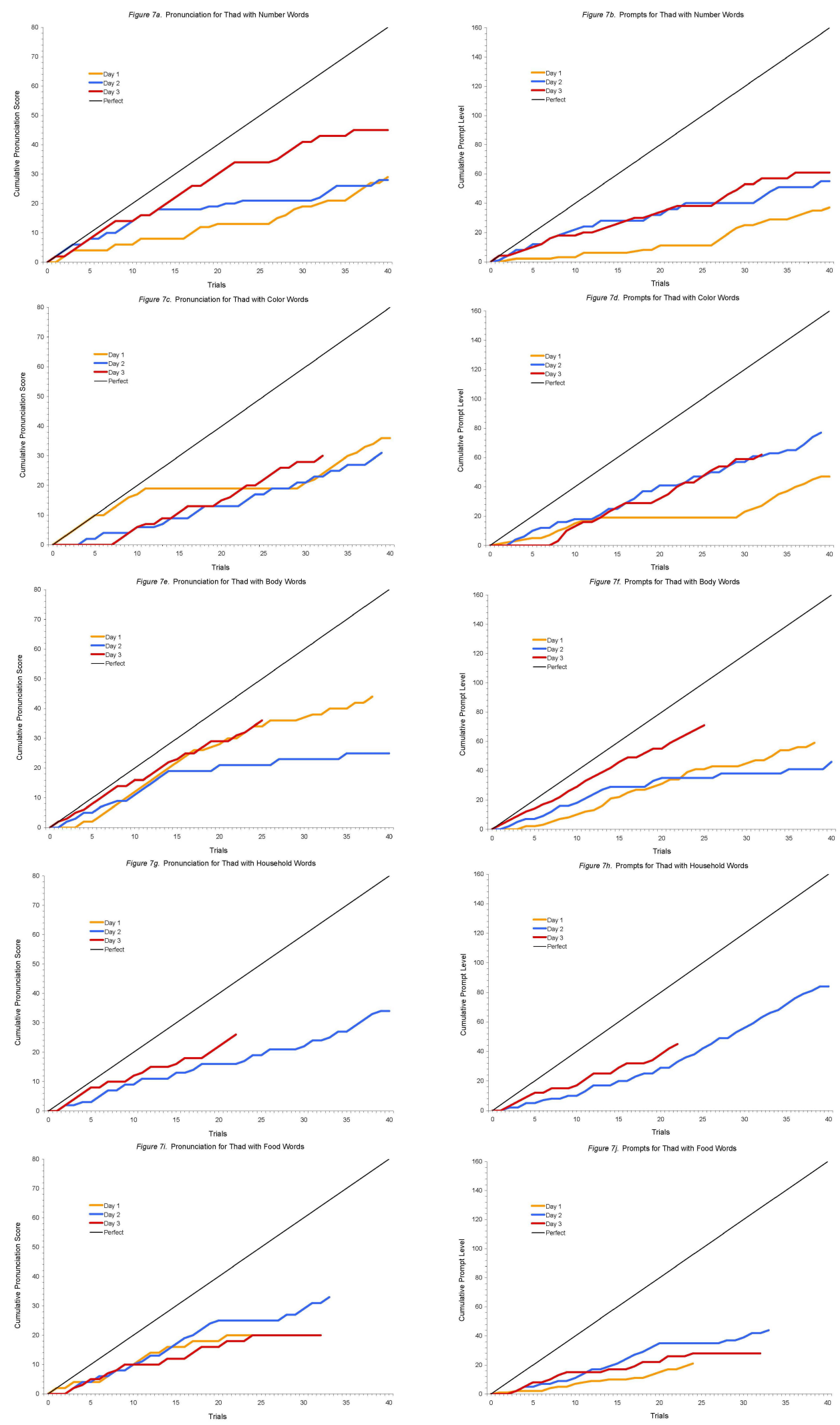
Figure 8. Percent of Total Trials with Use (Values in Bars are Number of Trials)

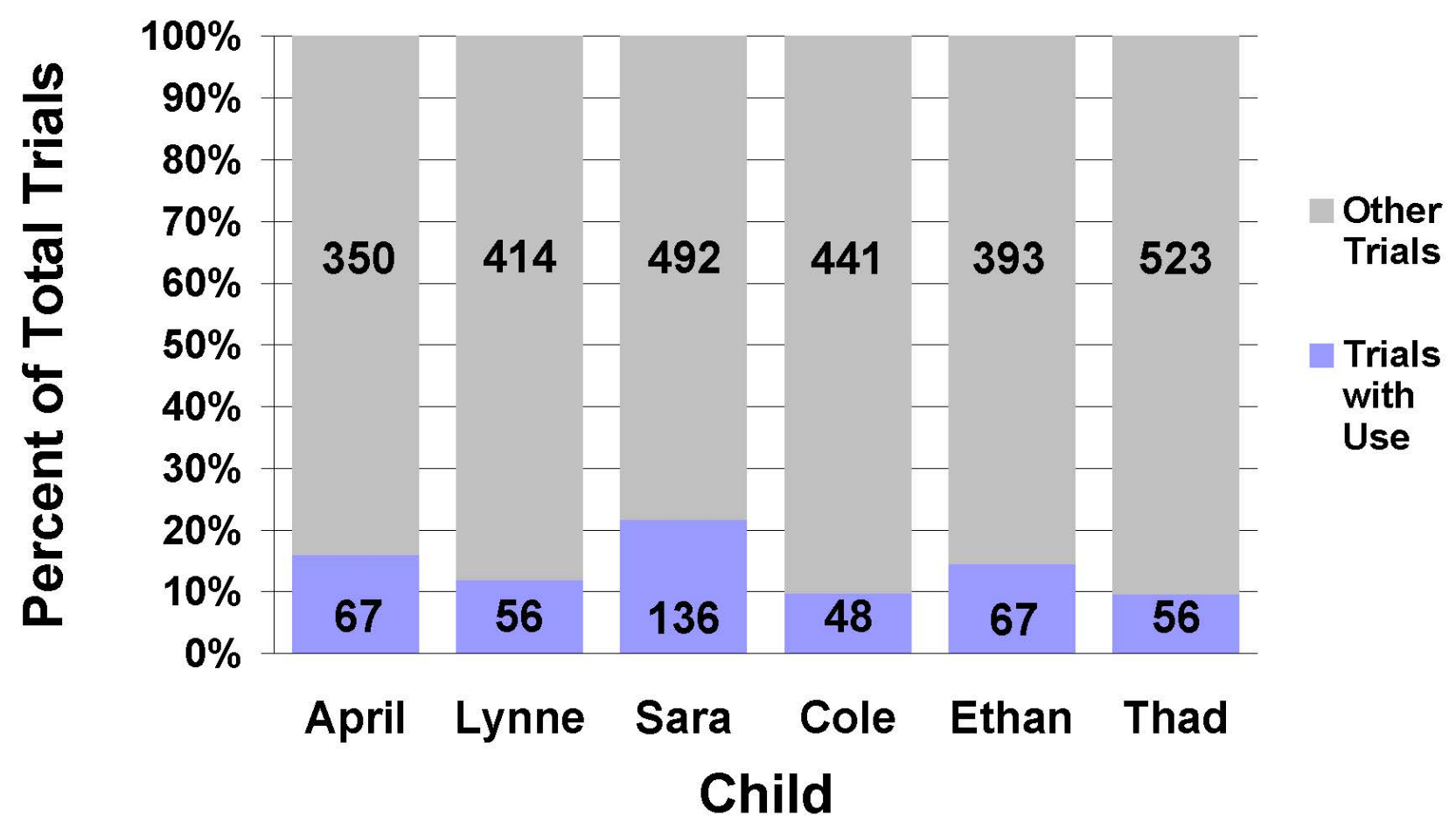


Figure 9. Percent of Trials with Use by Prompt Level (Values in Bars are Number of Trials)

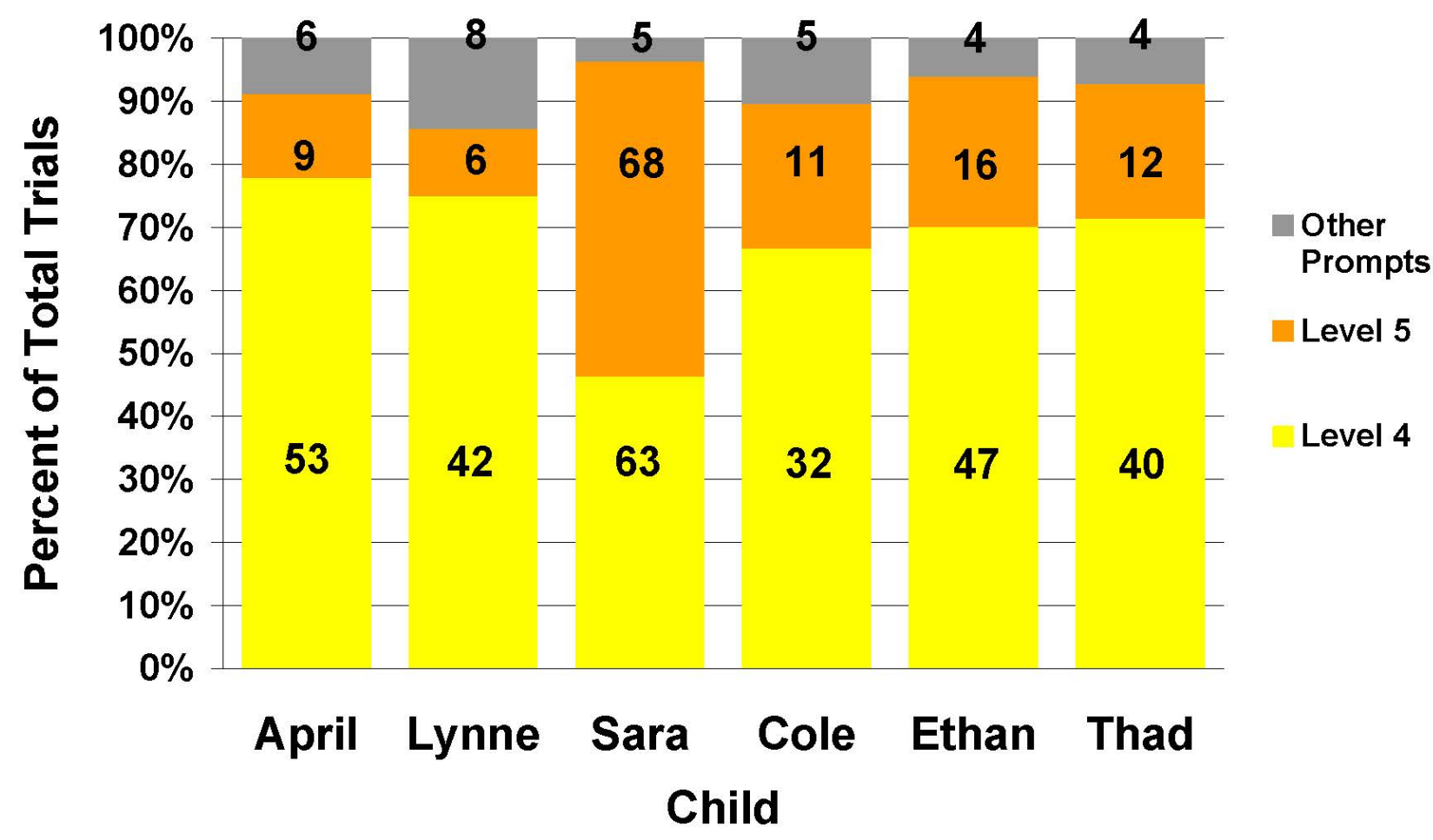




\section{Appendix A}

Sample Score Sheet for Pre-Test and Post-Test

Child:

Code:

Pre-test:___ Post-test:

Correct Identification $=\boldsymbol{V}$; Incorrect Identification $=\varnothing$

\begin{tabular}{|c|c|c|c|c|c|c|}
\hline \multicolumn{2}{|c|}{ Picture Card One } & \multicolumn{3}{|l|}{ Date: } & \multicolumn{2}{|c|}{ Score: ___ $/ 6$ correct } \\
\hline $\begin{array}{c}\text { Picture } \\
\text { Identified }\end{array}$ & blue & milk & mom & four & leg & table \\
\hline $\begin{array}{l}\text { Word } \\
\text { Spoken }\end{array}$ & & & & & & \\
\hline blue & & & & & & \\
\hline leche & & & & & & \\
\hline mom & & & & & & \\
\hline cuatro & & & & & & \\
\hline pierna & & & & & & \\
\hline table & & & & & & \\
\hline
\end{tabular}

Picture Card Two
\begin{tabular}{|c|l|l|l|l|l|l|}
\hline $\begin{array}{c}\text { Picture } \\
\text { Identified }\end{array}$ & dad & eyes & green & bread & three & bed \\
\hline $\begin{array}{c}\text { Word } \\
\text { Spoken }\end{array}$ & & & & & & \\
\hline padre & & & & & & \\
\hline eyes & & & & & & \\
\hline verde & & & & & & \\
\hline pan & & & & & & \\
\hline three & & & & & & \\
\hline bed & & & & & & \\
\hline
\end{tabular}




\title{
Appendix B
}

Sample Lesson Plan for Themed Spanish Activities

\author{
Week Six - Food \\ milk-leche bread-pan cheese-queso meat-carne candy-dulce
}

\section{Activity 3: Grocery List Match-Up Game $\quad$ Date of Lesson: October 31, 2014}

\section{Description of Activity:}

o The children will work individually or in a small group with the instructor

o The children will pick cards placed upside down to try to find two pictures that match; the cards are pictures of the vocabulary words with the English and Spanish labels written on them

o As the children match the cards, they put them in their "grocery bag" and mark the items off their grocery list with a dry erase marker

o Throughout the game, the children will identify the words in English and Spanish, repeating after the researcher

\section{Goals of Activity:}

o Following directions and steps in the game, while respecting other players

o Making connections between the matching pictures and the written English and Spanish words

o Engaging in play and peer interaction by helping each other identify words and commenting about vocabulary words and matches

\section{Materials:}

o Picture cards labeled in English and Spanish

o Paper “grocery” bags (2)

o Laminated grocery lists (2)

o Dry erase markers (2)

Objectives for Lesson (WV Content Standards):

o Social/Emotional Development 2.8 - Begins to share materials and experiences and take turns

o Language/Literacy 2.12 - Recognizes a word as a unit of print

o Mathematics 1.5 - Uses comparative words such as more, less, fewer, equal to 


\section{Appendix C}

Sample Data Sheet for Coding Video Recordings of Activities

Child:

Theme:

Time In:
Date:

Day: 123

Time In:

Time Out:

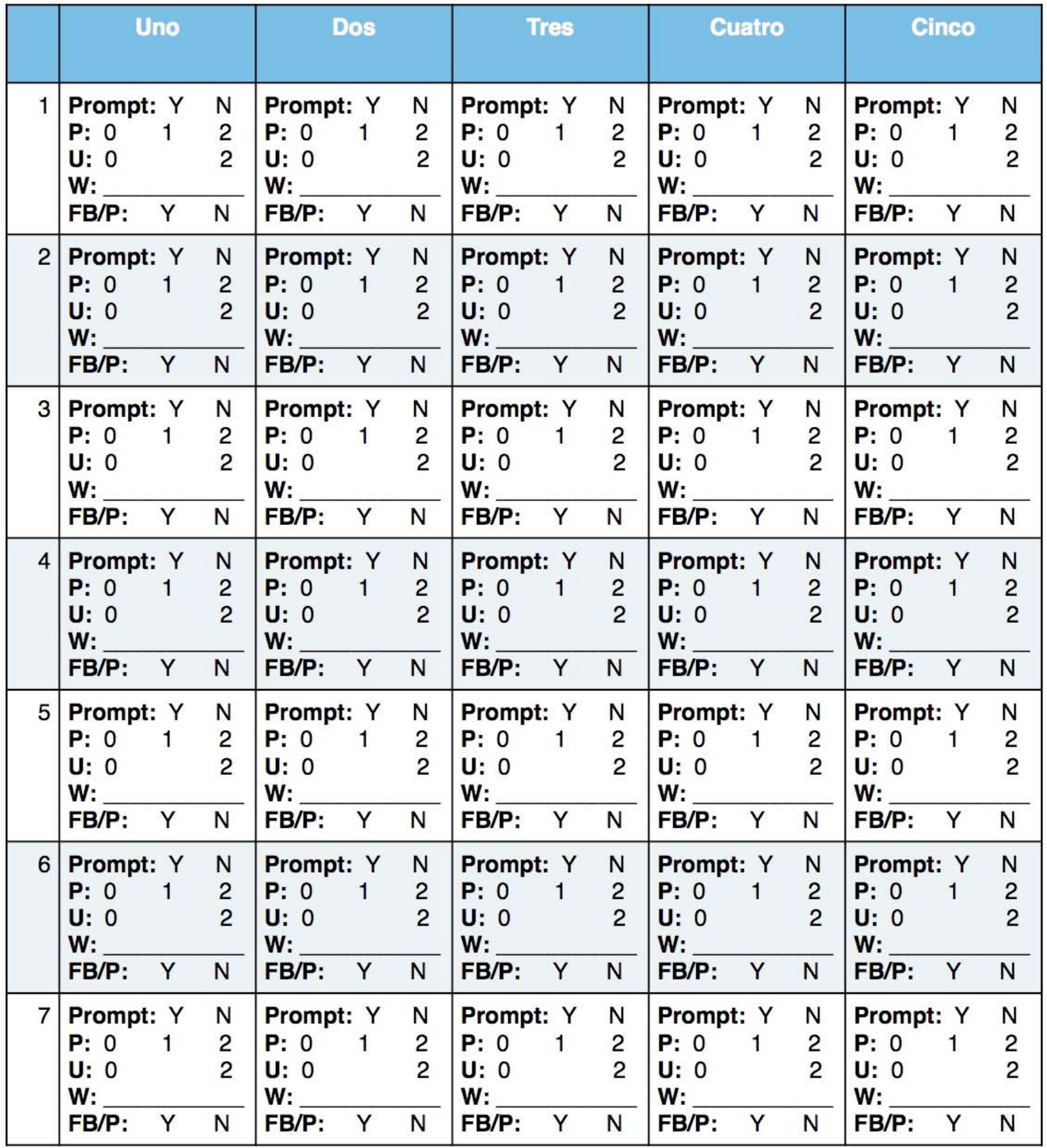

